\title{
The effect of film thickness on polypyrrole actuation assessed using novel non-contact strain measurements
}

Daniel Melling, Stephen Wilson and Edwin Jager

\section{Linköping University Post Print}

\section{Tweet}

N.B.: When citing this work, cite the original article.

Original Publication:

Daniel Melling, Stephen Wilson and Edwin Jager, The effect of film thickness on polypyrrole actuation assessed using novel non-contact strain measurements, 2013, Smart materials and structures (Print), (22), 10, . http://dx.doi.org/10.1088/0964-1726/22/10/104021

Copyright: Institute of Physics: Hybrid Open Access http://www.iop.org/ 


\title{
The effect of film thickness on polypyrrole actuation assessed using novel non-contact strain measurements.
}

\author{
Daniel Melling ${ }^{1,2,3 *}$, Stephen Wilson ${ }^{2}$ and Edwin W. H. Jager ${ }^{3,4}$ \\ ${ }^{1}$ Cranfield University, Dept. of Materials, MK43 OAL Cranfield, UK \\ ${ }^{2}$ University of Dundee, IMSaT, 1 Wurzburg Loan, Dundee, DD2 1FD, UK \\ ${ }^{3}$ Linköping University, ITN, Organic Electronics, 60174 Norrköping, Sweden \\ ${ }^{4}$ Linköping University, IFM, Biosensors and Bioelectronics, 58183 Linköping, Sweden \\ * Corresponding author’s e-mail: d.melling@dundee.ac.uk
}

\begin{abstract}
Micro-actuators have been developed that exploit the electrochemically induced volume change of the electro-active polymer polypyrrole. The strain regime is inherently complex at a physical level and whilst volume change can be estimated indirectly using, for instance, bending beam theory, such methods become unreliable for large deflections owing to limitations in the mathematical model. A new non-contact measuring technique based on laser micrometry is presented to characterize the timedependent expansion of electro-active films such as polypyrrole. Measurements have been made which demonstrate that the observed strain is dependent on film thickness. The new measurement technique is straightforward to perform and it is anticipated that it can be used for future materials development and performance assessment, including long term stability evaluations and operational failure studies of the films.
\end{abstract}

\section{Introduction}

Conjugated polymers (CP) such as polypyrrole (PPy) have been advocated as novel actuators, principally in healthcare and biomedicine, with applications and potential applications that include implants, stents, articulating links, robots, micro-valves, exoskeletons and prostheses ${ }^{1,} \quad 2$. Characteristically they operate silently, at low applied voltages, generating moderate forces and relatively high displacements. They are compliant and relatively lightweight in comparison with competing transducer materials such as shape memory alloys and they are adaptable for mass fabrication.

The actuating principle of CPs such as PPy is somewhat similar to that of natural muscles, being electrically controlled, wet, and soft. Typically PPy undergoes electrochemical oxidation or reduction in the presence of an ionic solution, when a low potential $(\sim 1 \mathrm{~V})$ is applied, and this is accompanied by a macroscopic change in volume. The volume change has associated tri-axial strain and it is predominantly caused by the insertion or ejection of both ions and solvent into the polymer matrix ${ }^{3,4}$. For PPy doped with small, mobile anions (a) in contact with an electrolyte containing both mobile cations and anions the reaction can be summarized as: 


$$
\left.\operatorname{PPy}^{+}\left(\mathrm{a}^{-}\right)+\mathrm{e}^{-} \leftrightarrow \operatorname{PPy}^{0}+\mathrm{a}^{-}(\mathrm{aq}) \quad \text { (eq. } 1\right)
$$

When reducing the polymer to its neutral state anions a- are expelled and when oxidizing the polymer anions are inserted into the polymer matrix in order to compensate for the charge imbalance. For PPy doped with large, immobile anions $\mathrm{A}^{-}$in contact with an electrolyte containing small mobile cations $\mathrm{M}^{+}$the reaction can be summarized as:

$$
\operatorname{PPy}^{+}\left(\mathrm{A}^{-}\right)+\mathrm{M}^{+}(\mathrm{aq})+\mathrm{e}^{-} \leftrightarrow \operatorname{PPy}^{0}\left(\mathrm{~A}^{-} \mathrm{M}^{+}\right) \text {(eq. 2) }
$$

Cations $\mathrm{M}^{+}$are inserted when PPy is reduced and expelled when the polymer is oxidized. In the former case, the volume typically expands in the oxidized state, i.e. when a positive potential is applied, and in the latter case the volume of the polymer expands in the reduced state, i.e. when a negative potential is applied. This principle has been used to create actuators both at macroscale ${ }^{5-7}$ and microscale $e^{8,9}$. The materials generate higher force per unit area, typically more than $5 \mathrm{MPa}$, than mammalian skeletal muscles $(0.35 \mathrm{MPa})^{10}$. For small loads the observed strain is typically $1-10 \%$ compared to $\sim 20 \%$ for natural muscles (although strains up to 35\% have been demonstrated in a few cycles only ${ }^{11}$ ). These valuable characteristics open up new possibilities for device engineering, especially for robotics and prosthetics, and it is anticipated that further improvements will become possible as the materials reach higher states of development.

The generated strain can be estimated indirectly from the bending of a bilayer structure using bending beam theory ${ }^{3}$. Whilst this technique is relatively straightforward, some uncertainty surrounds its use, especially for large deflections, since it uses a simplified geometrical model ${ }^{12}$. In addition, the strain regime that pertains in these materials during actuation is inherently complex. Although ion intercalation is the predominant cause of the volume change ${ }^{3}$, solvent swelling ${ }^{4}$, conformational changes ${ }^{13}$ and coulombic repulsion of the polymer chains ${ }^{14}$ also contribute to the volume change and concomitant tri-axial stress. Furthermore the strain regime exhibits time variance linked to ion and solvent transport within the microstructure. It is well established that the volume change of PPy(DBS) is anisotropic, that is the out-of-plane strain is much larger than the in-plane $\operatorname{strain}^{15,16}$ and is most probably caused by the lamellar microstructure of PPy(DBS) orientated preferentially in planes parallel to the substrate ${ }^{17,18}$. However, it is probable that one or more of these factors could be influenced significantly by geometry (shape) and physical constraints (bond-line), leading to anisotropy in the generated strains.

Direct strain measurements of CP strips clamped in a tensile tester have been conducted, providing evidence to support the above view, demonstrating that the measured strain is dependent on the applied load $^{19}$. During activation the electric potential along the PPy strip is non-uniform due to the so-called iR drop and thus the redox reactions are also non-uniform in the linear direction which effectively leads to an underestimate of the observable strain ${ }^{20,21}$. An alternative approach involves line-scanning micron-sized PPy squares using AFM. This method is highly effective for localized observations in the nanometre to micrometre size range, whilst being relatively time-consuming to perform $^{15,22}$. As reported, the shape of the AFM probe may introduce artefacts due to convolution between the tip and the polymer squares ${ }^{15}$. Thus there is an ongoing need to study strains in situ using non-contact methods that do not impede the material.

In this paper, we present a novel method for non-contact out-of-plane strain measurements based on laser scanning micrometry and we demonstrate its capabilities by investigating the effect of layer thickness on the volume change. 


\section{Materials and Methods}

\subsection{Laser scan micrometry}

The new approach uses a laser scanning micrometer (LSM), to make in situ, non-contact measurements of dimensional changes at every stage of the actuation cycle, thereby allowing a range of performance metrics to be calculated.

The basic principle of operation is illustrated in figure 1. The LSM repeatedly scans a line in one direction at high speed. A gold wire working electrode (AuWE) coated with a PPy film inserted in the beam casts a shadow, equal to its diameter, onto the LSM detector. As the dimensions of the polymer film change the shadow cast on the detector changes accordingly. By noting the initial diameter of a cross-section of the Au wire, PPy film thicknesses can be calculated along with a variety of other performance metrics. The output signal from the LSM (Mitutoyo LSM-501H) and its controller (Mitutoyo LSM-6100) was synchronised with that from a potentiostat (Metrohm $\mu$ AUTOLAB III or Autolab PGSTAT20) and recorded simultaneously, providing a direct comparison with electrochemical data from experiments controlled by the potentiostat and associated software (GPES).

Figure 1. Plan view of the setup illustrating the principle of dimensional measurement using the LSM. (a) Shows the shadow cast by the cross-section of the PPy coated AuWE. (b) Shows the increase in the shadow due to the increase in the diameter caused by the expansion of the polymer film.

The LSM was side mounted and securely positioned by means of a supporting frame to which antivibration gel feet were fitted to the base. An electrically insulating electrode support table was secured to the frame and positioned above the LSM. This support was capable of $\mathrm{x}-\mathrm{y}-\mathrm{z}$ movement and allowed the precise positioning of the electrodes used during polymerization and actuation measurement. A lab jack was used to raise and lower the electrochemical cell facilitating its exchange. The actuation setup is illustrated in figure 2. The same electrochemical cell was used for both polymerization and actuation measurement. The cell had a path length of $3 \mathrm{~cm}$ and a volume of $50 \mathrm{ml}$. It was made of transparent plastic and had a rectangular cross-section with opposite faces that were parallel. This allowed the LSM beam to be incident normally and pass through the cell without being refracted by the plastic walls of the container or the electrolyte used to actuate the polypyrrole film. In this respect the actuation cell acted like a large "cuvette" typically used to make UV or colorimetric measurements.

The LSM is calibrated within the factory and supplied with a calibration gauge set to check the performance of the LSM and recalibrate when necessary. Regular checks on the stability of the LSM measurement revealed excellent stability and it was not necessary to recalibrate the LSM during the time that we made our measurements.

Figure 2. (a) A depiction of the electrochemical cell arrangement used to make actuation measurements. The scanning laser passes through the transparent electrochemical cell undisturbed until it meets the PPy coated AuWE which blocks its path and casts a shadow on the detector equal to its diameter. (b) a photograph of the setup during actuation measurement.

When set in its lowest resolution setting the LSM has a linear range of $50 \mu \mathrm{m}$ with a resolution of $0.01 \mu \mathrm{m}$ and a repeatability of $\pm 0.05 \mu \mathrm{m}$. This has allowed performance metrics for films as thin as one micron to be determined. To achieve this accuracy of measurement the work piece has to be 
accurately positioned to be within the region of most accurate measurement in the measuring region of the LSM.

\subsection{Actuation metrics}

The polymer films are first polymerized in-situ onto a AuWE (see figure 2(b)) and actuated unloaded until they reach a steady state. The cylindrical geometry of the films allows for the out-of-plane (diametrical) determination of both reversible and irreversible expansions and strains providing information on the rage of movements both within a redox cycle and over many cycles. In addition, information on how quickly the films can actuate is provided by absolute reversible expansion rates, reversible strain rates and the times to reach $90 \%$ maximum reversible expansion.

Currently, there is no universally agreed standard way of evaluating EAP performance. Therefore, we have adopted a range of actuation metrics commonly used by others ${ }^{10,22}$ to permit a comparison between different reported data. Metrics used to assess the extent of movement of the films are shown in table 1. In addition to these metrics we made assessment of how quickly the films moved using three metrics (see figure 3). The first of these was the maximum expansion rate (speed) during each scan. This metric was obtained by determining the gradient of the approximately linear part of the actuation profile during the first part of each scan, this being within the first seconds after switching, and is an absolute metric. A second metric, the maximum strain rate, during each scan was calculated. As with strain, maximum strain rate is a relative metric, which relates the maximum speed during a scan to the film thickness. The metric is calculated by dividing the maximum speed by the film thickness at the start of the range at which the gradient is evaluated. A third metric that we have employed is the time taken for the film to expand to $90 \%$ of its maximum value during the scan.

Table 1. Expressions used to calculate expansion and strain. Key: AuWE (gold working electrode), $R$ (general term for radius), $\mathrm{R}_{\mathrm{Au}}$ (radius of AuWE), $\mathrm{R}_{\mathrm{o}}$ (initial radius of the "as polymerized" PPy film + $R_{\text {Au }}$ ), $R_{\text {red }}$ (radius of the fully reduced PPy film $+R_{\text {Au }}$ ), $R_{\text {oxid }}$ (radius of the fully oxidized PPy film + $\mathrm{R}_{\mathrm{Au}}$ ).

Figure 3. Metrics used to represent how fast the PPy films actuate: expansion rate (speed), strain rate and time taken to reach $90 \%$ maximum reversible expansion.

\subsection{Experimental}

A three electrode electrochemical cell arrangement was employed during polymerization and actuation measurement. The same working electrode and type of reference electrode was used for polymerization and actuation but the counter electrodes employed were different. The reference electrode (RE) used was a $\mathrm{Ag} / \mathrm{AgCl}$ reference electrode obtained from BASi. A gold working electrode (AuWE) was made using high purity gold wire obtained from Goodfellows and had a diameter of approximately $500 \mu \mathrm{m}$. The gold wire was electrically insulated for most of its length but had an exposed length of $10 \mathrm{~mm}$ towards its lower end, on which polymer films were electrosynthesised. In addition to providing a surface for polymer growth the gold working electrode provided a means to position the film precisely within the measurement region of the LSM. The counter electrode used during polymerization was cylindrical (diameter $20 \mathrm{~mm}$, height $30 \mathrm{~mm}$ ) and constructed from acetate sheet (substrate/support) on which a layer of chromium (30 A) had been first evaporated to act as an adhesion layer for the gold layer $(2000 \AA)$ that was then evaporated to provide the active CE surface. The use of a cylindrical CE of this type ensured that the separation $(10 \mathrm{~mm})$ between the CE and the AuWE was the same when placed along the central axis of the CE and also allowed for a more uniform field along the length of the AuWE. The cylindrical CE was slightly 
raised so as to be above the scan plane of the LSM to allow direct monitoring of film growth in realtime during polymerization.

Films were polymerized using aqueous solutions of $0.1 \mathrm{M}$ pyrrole (Py, Sigma Aldrich, vacuum distilled prior to use) and 0.1 M sodium dodecylbenzenesulphonate (NaDBS, Purity > 95\%, Hardtype, TCI Europe). The water used was deionized Millipore water. Polymerization was undertaken at room temperature using a constant potential of $0.55 \mathrm{~V}$ vs. Ag/AgCl.

PPy films were polymerized in-situ within the measuring region of the LSM on to the cylindrical surface of the AuWE. This allows films of precise thickness to be grown by monitoring the change in the diameter of the WE using the LSM.

After the freshly prepared (as-polymerized) films were synthesised to the required thickness, they were rinsed using deionized water to remove traces of polymerization solution and immersed in $40 \mathrm{ml}$ of freshly prepared actuation solution. The position of the AuWE was not changed throughout the procedure ensuring that actuation measurements where undertaken on the same cross-section of the polymer coated AuWE. The actuation solution was 0.1 M NaDBS (Sigma Aldrich) in DI water and filtered using a $0.2 \mu \mathrm{m}$ nylon syringe filter to reduce potential interference from particulate matter. The raising and lowering of the electrochemical cell was facilitated by means of the lab jack.

The as-polymerized films were actuated with minimal delay after polymerization. The same cell that was used during polymerization was used during actuation measurement, as were the electrodes, with the exception that the CE was replaced with a flat rectangular shaped platinized $(2 \mu \mathrm{m})$ titanium mesh electrode with dimensions $(12 \mathrm{~cm} \times 2.5 \mathrm{~cm})$ supplied by The Ti Shop, positioned to one side of the cell and outside the scan range of the laser (See figure 2 (b)). The separation between the WE and CE in this arrangement was $3 \mathrm{~cm}$. All of the prepared films were actuated using a square wave potential of $0 \mathrm{~V}(200 \mathrm{~s})$ and $-1 \mathrm{~V}(200 \mathrm{~s}) \mathrm{vs}$. $\mathrm{Ag} / \mathrm{AgCl}$, unless otherwise mentioned. At these potentials the films are fully oxidized $(0 \mathrm{~V})$ and fully reduced $(-1 \mathrm{~V})$ as determined using cyclic voltammetry. The PPy(DBS) films contract during the oxidation scan and expand during the reduction scan (eq. 2). The actuation sequence was selected to start at $0 \mathrm{~V}$ vs. $\mathrm{Ag} / \mathrm{AgCl}$ to obtain a baseline and assess the stability of the LSM reading. Films were actuated until a "stable state" was attained in which the cycles were fully reversible. Both the current and diameter reading were recorded with the use of Autolab GPES software. All measurements were made close to the mid-point of the cylindrical PPy samples (length $=10 \mathrm{~mm}$ ). Given that the samples had a thickness (max thickness $=10 \mu \mathrm{m}$ ) to length ratio of at least 1:1000, edge effects were not expected to influence the results. By using a cylindrical rather than planar surface, perfect $90^{\circ}$ alignment of the surface of the sample to the laser "ribbon" is achieved.

\section{Results}

\subsection{PPy synthesis}

We were able to grow good quality PPy(DBS) films of uniform thickness and showing the typical cauliflower like surface ${ }^{23}$. The LSM was able to follow the growth of the PPy film perfectly as can be seen in figure 4. The increase in film thickness was found to be approximately linear although at times slight instability was evident in the LSM reading. This instability had a greater tendency to occur early on in the polymerization where the current flow was greatest. 
Figure 4. Graphs showing the current and film thickness recorded during the polymerization of a 10 $\mu \mathrm{m}$ PPy film. Growth is essentially linear with slight instability and "spiking”. Spiking might be due to the presence of particulate matter in the unfiltered polymerization solutions.

\subsection{General features of the actuation}

Our new technique can also accurately follow the electrochemically induced actuation of the PPy film. Figure 5 shows a typical recording of the actuation profile.

Figure 5. (a) A typical profile of an actuation sequence. In this case PPy film was $10 \mu \mathrm{m}$ thick (b) Enlarged ("zoomed in”) section showing details of a few cycles.

A number of general features associated with the actuation of PPy(DBS) films are illustrated in figure 6. From figures 5 and 6 it can be clearly seen that the profile has two components to the expansion, which are displayed by all PPy(DBS) films: a reversible and an irreversible expansion, with both components reaching a maximum over different time scales. The reversible expansion typically takes between five to ten cycles to reach a maximum, steady state (figure 6) whereas the irreversible expansion can take tens of cycles to reach its maximum, steady state. Once the irreversible expansion has reached a maximum value, the actuations stabilize and are completely reversible. We term this "the steady state" of the actuating film. The greatest increase in the irreversible expansion occurs during the first reduction scan and is believed to be the result of both ion and solvent movements, 24

We later show that the reversible and irreversible expansion is dependent upon both the film thickness and cycling conditions, although it is also likely to be dependent upon the materials properties of the film as determined by different synthesis conditions such as the modulus of elasticity.

Figure 6. Changes in reversible expansion and irreversible expansion with cycle number for a $10 \mu \mathrm{m}$ film of PPy(DBS). Note: the reversible component stabilises relatively quickly and reaches its maximum early on in the sequence, typically by cycle 10 . After a large increase during the first cycle, the irreversible expansion, displays a slower more gradual increase, reaching a stable maximum between 70-80 cycles.

Metrics obtained during the stable state are more representative of the long term behaviour and final dimensions of the actuating film and as such are more relevant to those engaged in the design and construction of polymer actuators than metrics determined earlier on in the sequence e.g. cycle 10 .

Another important thing to notice is that the majority of the expansion occurs early on in each cycle, occurring within the first seconds and is approximately linear. Once the polymer has undergone approximately $90 \%$ of its maximum reversible expansion, the expansion rapidly slows down before reaching a maximum value. The actuation mechanisms for polypyrrole are well documented to explain the reversible expansion of the films, with the principle mechanism being ion transport into and out of the polymer from the electrolyte (eq. 1 or eq. 2) and osmotic swelling, 4, 7, 24. Figure 6 also reveals a rapid increase in the apparent film thickness (spikes) on switching the potential from $-1 \mathrm{~V}$ to $0 \mathrm{~V}$ for the $10 \mu \mathrm{m}$ films. The first 20 seconds after switching is displayed in greater detail in figure S1. An "upward spike" is observed when the polymer is switched from the reduced (expanded) state to the oxidized (contracted) state. A smaller "downward spike" was observed for $10 \mu \mathrm{m}$ films on switching from $0 \mathrm{~V}$ to $-1 \mathrm{~V}$. A small downward spike was observed for the $5 \mu \mathrm{m}$ films but no upward spike. For the $1 \mu \mathrm{m}$ films no spikes were observed even when the data point interval was lowered to $0.5 \mathrm{~s}$. In the period immediately after switching the potential there will be a large change in the concentration of ions in the electrolyte near the polymer surface as ions leave or enter the polymer. If 
this change in concentration is large enough relative to the surrounding bulk electrolyte, large changes in the refractive index of short duration will occur. This phenomenon is a form of atmospheric refraction termed the "mirage effect" and has been used to study ion transport in polymers ${ }^{25,26}$

The effect of different cycle times can be seen in figure 7. Here a $10 \mu \mathrm{m}$ film was polymerized onto the surface of a $500 \mu \mathrm{m}$ diameter AuWE to give a combined initial diameter of $520 \mu \mathrm{m}(500+2(10)$ $\mu \mathrm{m})$ (region A). The as-polymerized film was then actuated with a cycle time of $400 \mathrm{~s}$ until it reached the stable state (region B). The cycle time was then increased to $2000 \mathrm{~s}$ for one cycle (region C) and then decreased to $100 \mathrm{~s}$ for ten cycles (region D).

By comparing the vertical separation between local peak maxima and minima in figure 7 (arrows R1 to R3) it can be seen that a decrease in cycle time results in a decrease in reversible expansion. This might have been expected. However, by comparing the vertical separation between the peak minima and the horizontal axis, which corresponds to the initial diameter of the PPy/AuWE (520 $\mu \mathrm{m})$, it can be seen that a decrease in cycle time leads to an increase in irreversible expansion.

Figure 7. The effect of different cycle times on the reversible and irreversible expansion for the same $10 \mu \mathrm{m}$ film of PPy(DBS). Region B cycle times: $400 \mathrm{~s}$ (-1 V (200 s), 0 V (200 s)); Region C: $2000 \mathrm{~s}$ (-1 V (1000s), 0 V (1000s)); Region D: 100 s (-1 V (50 s), 0 V (50 s)).

\subsection{The effects of film thickness}

The actuation of 1, 5 and $10 \mu \mathrm{m}$ PPy(DBS) films was undertaken using three replicate samples at each thickness. The cycle length was chosen to be $400 \mathrm{~s}$ in order to guarantee fully expanded/contracted PPy films. Typical sequences for these films are shown in figure 8 . The overlay shown in figure 8 (a) reveals the relative sizes of important features such as: the reversible and irreversible expansion and the time taken to reach the stable state. It can be seen that both the reversible and irreversible expansion increases with film increasing thickness. In addition it can be seen that thicker films take longer (more cycles) to reach "the stable state" corresponding to the state of maximum irreversible expansion.

Figure 8 (a) Overlay of typical sequences obtained for 1,5 and $10 \mu \mathrm{m}$ PPy(DBS) films. (b-d) Enlarged (zoomed) cycles taken from the end of the sequence showing the actuation profiles in greater detail.

A range of metrics where determined in order to fully assess the performance of these films and are displayed in table S1. These metrics reveal both the magnitude and rate of diametrical (out-of-plane) strain that takes place during actuation. In addition they reveal differences between the reduction and oxidation scans and changes that occur with cycle number.

All of the films in the range 1 to $10 \mu \mathrm{m}$ undergo reversible and irreversible expansion and strain. The reversible expansion increases and the reversible strain decrease with increase in film thickness as shown in figures 9 (a) and 9 (b). There is no evidence of a change in reversible expansion between cycle ten and the steady state. The irreversible expansion increases and the irreversible strain decreases with increase in film thickness. No change in the irreversible expansion and strain was observed for $1 \mu \mathrm{m}$ films on going from cycle ten to the steady state. However, a significant increase in irreversible expansion and strain was observed for 5 to $10 \mu \mathrm{m}$ films on going from cycle 10 to the steady state.

Figure 9. (a) Expansion vs. film thickness and (b) Strain vs. film thickness. Error bars $=1$ SD. 
Both the speed and strain rate decrease during the reduction and oxidation scans with increase in film thickness as revealed by figures 10 (a) and 10 (b). In addition, both the expansion rate and strain rate is greater during the reduction scan than during the oxidation scan for films of the same thickness. There is no significant evidence of a change in expansion rate and strain rate between cycle 10 and steady state.

The same pattern is shown when the speed is expressed in the other metric. The time taken for the films to expand to $90 \%$ maximum reversible expansion increases with film thickness during both the reduction and oxidation scans as seen in figure 10 (c). Again, the times are greater during the oxidation scan than during the reduction scan.

Figure 10. (a) Expansion rate vs. thickness (b) Strain rate vs. thickness. (c) Time to 90\% maximum expansion. Error bars $=1 \mathrm{SD}$

\section{Discussion}

PPy(DBS) films in the range 1 to $10 \mu \mathrm{m}$ undergo a diametrical expansion, which comprises two components, a reversible part and an irreversible part. The combined total expansion increases with film thickness. The reversible expansion increases from $0.87 \pm 0.2 \mu \mathrm{m}$ for a $1 \mu \mathrm{m}$ film to $3.47 \pm 0.14$ $\mu \mathrm{m}$ for a $10 \mu \mathrm{m}$ film and the irreversible from $0.78 \pm 0.02 \mu \mathrm{m}$ to $3.75 \pm 0.78 \mu \mathrm{m}$. The reversible expansion stabilises quickly, after approximately 5-7 cycles, while the irreversible expansion takes much longer to stabilise and is highly dependent on the film thickness, up to 80 cycles for the $10 \mu \mathrm{m}$ film. Interestingly, both the reversible and irreversible strain decrease with increasing film thickness, from $47.13 \pm 3.00 \%$ to $25.21 \pm 0.79 \%$ and from $78.89 \pm 2.18 \%$ to $37.35 \pm 0.89 \%$, respectively. This reveals that a relatively smaller portion of the film is electroactive. A previous study of volume change in PPy(DBS) using an AFM has been undertaken by Smela and Gadegaard ${ }^{152}$. Despite our employing a different system (cylindrical vs. planar geometry) the observations and numbers fit each other well. They measured $40 \%$ for a $0.8 \mu \mathrm{m}$ film and $28 \%$ for a $3 \mu \mathrm{m}$ thick microfabricated film. The data fits well with the established view of the ion motion into and out of the polymer from the electrolyte (eq. 1 or eq. 2$)^{3,7,27}$ and solvent swelling, ${ }^{44}$ being the driving force of the volume change. The reversible expansion has two regimes: a fast expansion during the first few seconds where the expansion reaches up to $80-90 \%$ of the maximum expansion, followed by a slower expansion during the remaining period of the cycle. We attribute the fast expansion to the ion motion and the slower final expansion to the osmotic pressure. This can also be seen when we compare the expansion with the current (figure S2). The expansion profiles follow the reduction and oxidation current transients that have an initial peak with a very steep gradient occurring upon switching that decays away until a very small constant current is obtained.

PPy films have most probably an anisotropic density, more dense towards the Au surface and an anisotropic volume change, being larger towards the outer surface ${ }^{12}$. The lesser dense outer part allows for easy transport into and out the matrix of both ions and solvent therefor limiting the active part of the volume change to the few outer micrometres. Smela and Gadegaard studied mostly thin films, but also noticed a decrease in reversible out-of-plane strain with increasing film thickness above $1.5 \mu \mathrm{m}$ using the AFM.

The surprisingly large irreversible expansion was also noted in the aforementioned AFM study. We also noted that the largest increase in irreversible expansion occurs during the first cycle. A mechanism to account for the irreversible component is less well documented. It is recognised that the 
largest increase in the irreversible expansion occurs during the first actuation scan and has been attributed to the movement of solvent as well as ions into the polymer film as the polymer network becomes more open. Smela et al have shown that air dried PPy(DBS) expands on being placed in aqueous electrolyte prior to actuation ${ }^{22}$. In the work presented here, however, as-polymerized films were prepared and actuated immediately after formation and were not allowed to air dry.

An explanation for this behaviour is that during the first reduction scan solvent from the electrolyte along with hydrated cations $\left(\mathrm{Na}^{+}\right)$enter the polymer film, opening up the polymer matrix. On oxidation these solvent molecules remain in the polymer matrix ${ }^{28-30}$. Bay et al have shown that an osmotic pressure is generated by ionic components of the polymer ${ }^{4}$. These osmotic forces can force water molecules into the polymer film during electrochemical cycling in quantities far in excess of those of the mobile ion (ca. $\left.\mathrm{Na}^{+} .3 \mathrm{H}_{2} \mathrm{O}\right)^{31}$.

In order to investigate the role of passive solvent swelling we left an as-polymerized $5 \mu \mathrm{m}$ PPy(DBS) film immersed in 0.1 M NaDBS(aq) actuation solution without any external influence such as the application of an external electrical potential or change in temperature or $\mathrm{pH}$ over a period of 7 hours (see figure S3). It showed that the PPy film expanded $41 \%$. The irreversible expansion for a $5 \mu \mathrm{m}$ film under cycling is $\sim 68 \%$. It would therefore appear that the primary source of irreversible expansion for the $\mathrm{PPy}(\mathrm{DBS})$ films is indeed the result of solvent swelling, which is further increased by the cycling of the PPy film. It is known that the applied redox potential opens up the polymer matrix ${ }^{27,32}$. So the cycling probably aids in opening up the polymer matrix even more to allow for more "passive" expansion deeper into the PPy film. The expansion of polymers through solvent swelling is well known within the field of polymer science and is closely related to the state of the polymer network e.g. the extent of crosslinking and branching.

An alternative explanation for the large irreversible expansions observed during electrochemically cycling is that creep is occurring. Creep is known to occur within loaded PPy films ${ }^{33,34}$. In addition, the plasticizing effect of solvent molecules incorporated into polymer films is also $\mathrm{known}^{35,36}$. Although $\mathrm{PPy}\left(\mathrm{ClO}_{4}\right)$ films have been observed to deformation on actuation, we, like others ${ }^{22}$, did not note any wrinkling of actuated PPy(DBS) films upon microscopic examination.

We also noticed that the expansions depend on the cycle length employed. As can be seen in figure 7, longer cycle length results in more reversible expansion and less irreversible expansion. Interestingly the total expansion (reversible and irreversible) also increases with increasing cycle length. This fits with the diffusion model. It takes more time to diffuse deeper into the PPy matrix, although it seems that it is not possible to get diffusion into the full PPy depth. There is a steady state were maximum diffusion and thus expansion is reached. Interestingly the expansion rate is independent of the cycle length (see figure S4).

We have observed that there is a decrease in expansion rates and strain rates with increasing film thickness. This would indicate that the PPy material composition or density alters with increasing thickness. The outermost portion of the $1 \mu \mathrm{m}$ PPy appears to be a different "form" of PPy compared to the outermost portion of the 5 and $10 \mu \mathrm{m}$ PPy, otherwise they would move at the same expansion rate (speed). The other metrics that we have used during this study (time to $90 \%$ maximum reversible expansion) consistently show that thinner films expand more quickly than thicker films. Although strain rates were not given at different thicknesses in the AFM study, it was observed that the times taken for the films to expand to $80 \%$ of their maximum reversible expansion increased with increase in film thickness. It is also interesting to note that for the $1 \mu \mathrm{m}$ film the irreversible expansion also stabilises quickly, supporting the diffusion hypothesis. 
We have observed that the speed (reversible expansion rates) is faster during the reduction scan compared to the oxidation scan. The faster speed during reduction may be attributed to the fact that PPy has a higher electronic conductivity in the oxidised state ${ }^{37}$. The increased resistivity in the reduced state affects the electric field within the polymer. However, others have noted a faster speed during the oxidation scan than during reduction $\operatorname{scan}^{15}$. This might be attributed to the higher ion conductivity in the reduced state, in which the polymer has a more expanded, open, and swollen matrix $^{38}$. We also see that the speed increases with cycle number. This supports the hypothesis that the continuous cycling helps to open the polymer matrix, reducing the compaction ${ }^{27}$. The volume change of PPy is a complex process comprising mass transport, charge transport and chain movements ${ }^{39}$. Our experiments show that which of these (e.g. ionic vs. electronic conductivity) is the rate limiting step depends highly on the experimental conditions applied.

\section{Conclusions}

We have developed a new non-contact method for monitoring the out-of-plane strain of electroactive films that is quick and simple to perform and utilizes relatively inexpensive equipment. It provides a means to determine the out-of-plane expansion and strain of continuous films in the unloaded condition. The data generated can reveal many aspects of the CP behaviour. In addition to providing actuation metrics, the method could serve as a useful tool for optimizing actuation performance, undertaking synthesis studies and studying the long term stability and operational failure of actuating films. When combined with a feedback loop the method may be used to achieve automated control of film thickness during synthesis, e.g. in a production line.

We confirm that the PPy(DBS) films have large out-of-plane strains, up to 51\%. In addition, we have shown that the actuation performance of PPy films depends upon film thickness. Thicker films undergo larger absolute expansion (reversible and irreversible) but smaller relative movement (smaller reversible and irreversible strains). Thinner films are quicker (larger reversible expansion rates, strain rates and shorter times to $90 \%$ maximum expansion) than thicker films. In this respect, thinner films produce more "effective" and "responsive" actuating films compared to thicker films. However, we have shown that thicker films have the advantage of producing larger absolute expansions compared to thinner films and thus might be more useful in applications requiring a large stroke.

In addition we have shown that actuation performance is dependent upon the rate of cycling, with a shorter cycle time resulting in a smaller reversible expansion and larger irreversible expansion, than longer cycle times for films of the same thickness. Speed (expansion rate) on the other hand is independent of the cycle length.

\section{Acknowledgement}

The authors wish to express their sincere gratitude to Prof. Magnus Berggren (LiU-ITN), Prof. Anthony Turner (LiU-IFM) and Dr Alex Skordos (UC) for their support and José Martinez for measuring the data of figure S3.

Funding has been supplied by EPSRC grant: EPP/504880/1, EU-FP7-Erasmus, European Science Foundation COST Action MP1003 ESNAM (European Scientific Network for Artificial Muscles) and COST-STSM-MP1003-11581, Swedish Foundation for Strategic Research (SSF), Linköping University. 


\section{References}

1. C. Immerstrand, K. H. Peterson, K.-E. Magnusson, E. Jager, M. Krogh, M. Skoglund, A. Selbing and O. Inganäs, MRS bulletin 27 (6), 461-464 (2002).

2. $\quad$ S. A. Wilson, R. P. J. Jourdain, Q. Zhang, R. A. Dorey, C. R. Bowen, M. Willander, Q. U. Wahab, M. Willander, M. A. H. Safaa, O. Nur, E. Quandt, C. Johansson, E. Pagounis, M. Kohl, J. Matovic, B. Samel, W. van der Wijngaart, E. W. H. Jager, D. Carlsson, Z. Djinovic, M. Wegener, C. Moldovan, R. Iosub, E. Abad, M. Wendlandt, C. Rusu and K. Persson, Materials Science \& Engineering R-Reports 56 (1-6), 1-129 (2007).

3. Q. Pei and O. Inganäs, Journal of physical chemistry 96 (25), 10507-10514 (1992).

4. $\quad$ L. Bay, T. Jacobsen, S. Skaarup and K. West, J. Phys. Chem. B 105, 8492-8497 (2001).

5. Q. Pei and O. Inganäs, Advanced materials 4 (4), 277-278 (1992).

6. T. F. Otero, E. Angulo, J. Rodriguez and C. Santamaria, Journal of Electroanalytical Chemistry 341 (1-2), 369-375 (1992).

7. M. R. Gandhi, P. Murray, G. M. Spinks and G. G. Wallace, Synth. Met. 73, 247-256 (1995).

8. $\quad$ E. Smela, O. Inganäs and I. Lundström, Science 268, 1735-1738 (1995).

9. $\quad$ E. W. H. Jager, E. Smela and O. Inganäs, Science 290 (5496), 1540-1545 (2000).

10. J. D. Madden, R. A. Cush, T. S. Kanigan and I. W. Hunter, Synthetic Metals 113 (1-2), 185$192(2000)$.

11. T. Zama, N. Tanaka, W. Takashima and K. Kaneto, Polym. J 38 (7), 669-677 (2006).

12. E. Smela, M. Kallenbach and J. Holdenried, Journal of Microelectromechanical Systems 8 (4), 373-383 (1999).

13. T. F. Otero, H. Grande and J. Rodrîguez, Electrochimica Acta 41 (11-12), 1863-1869 (1996).

14. T. F. Otero and J. Padilla, Journal of Electroanalytical Chemistry 561 (SUPPL. 1), 167-171 (2004).

15. $\quad$ E. Smela and N. Gadegaard, Advanced Materials 11 (11), 953-957 (1999).

16. K. Svennersten, M. Berggren, A. Richter-Dahlfors and E. W. H. Jager, Lab on a Chip Miniaturisation for Chemistry and Biology 11 (19), 3287-3293 (2011).

17. X. Wang and E. Smela, Journal of Physical Chemistry C 113 (1), 359-368 (2009).

18. W. Wernet, Monkenbusch, M., Wegner, G., Mol. Cryst. Liq. Cryst. 118, p. 193-197. (1985).

19. G. M. Spinks, L. Liu, G. G. Wallace and D. Zhou, Advanced Functional Materials 12 (6+7), 437-440 (2002).

20. A. Della Santa, D. D. Rossi and A. Mazzoldi, Synthetic Metals 90, 93-100 (1997).

21. A. S. Hutchison, T. W. Lewis, S. E. Moulton, G. M. Spinks and G. G. Wallace, Synthetic Metals 113 (1-2), 121-127 (2000).

22. E. Smela and N. Gadegaard, J. Phys. Chem. B 105, 9395-9405 (2001).

23. C. O. Yoon, H. K. Sung, J. H. Kim, E. Barsoukov and J. H. Kim, Synthetic Metals 99 (3), 201-212 (1999).

24. M. J. M. Jafeen, M. A. Careem and S. Skaarup, Ionics 16 (1), 1-6 (2010).

25. C. Barbero, M. C. Miras, R. Kötz and O. Haas, Solid State Ionics 60 (1-3), 167-172 (1993).

26. C. A. Barbero and M. C. Miras, Anales des la Asociacion Quimica Argentina 91 (4-6), 1-40 (2003).

27. T. F. Otero, H. J. Grande and J. Rodriguez, Journal of physical chemistry B 101 (19), 36883697 (1997).

28. T. Matencio, M. A. De Paoli, R. C. D. Peres, R. M. Torresi and S. I. Cordoba de Torresi, Synthetic Metals 72 (1), 59-64 (1995).

29. R. M. Torresi, S. I. Córdoba de Torresi, T. Matencio and M. A. De Paoli, Synthetic Metals 72 (3), 283-287 (1995).

30. M. A. De Paoli, R. C. D. Peres, S. Panero and B. Scrosati, Electrochimica Acta 37 (7), 11731182 (1992).

31. G. Maia, R. M. Torresi, E. A. Ticianelli and F. C. Nart, Journal of Physical Chemistry 100 (39), 15910-15916 (1996).

32. T. F. Otero, H. Grande and J. Rodriguez, J. Phys. Chem. B 101 (42), 8525-8533 (1997).

33. J. D. Madden, D. Rinderknecht, P. A. Anquetil and I. W. Hunter, Sensors and Actuators A: Physical 133 (1), 210-217 (2007). 
34. K. Kaneto, T. Shinonome, K. Tominaga and W. Takashima, Japanese Journal of Applied Physics 50 (9 PART 1) (2011).

35. H. Batzer and U. T. Kreibich, Polymer Bulletin 5 (11-12), 585-590 (1981).

36. C.-C. Pai, R.-J. Jeng, S. J. Grossman and J.-C. Huang, Advances in Polymer Technology 9 (2), 157-163 (1989).

37. H. Mao and P. G. Pickup, Journal of the American Chemical Society 112 (5), 1776-1782 (1990).

38. H. Mao and P. G. Pickup, Journal of Physical Chemistry 93 (17), 6480-6485 (1989).

39. X. Wang and E. Smela, Journal of Physical Chemistry C 113 (1), 369-381 (2009). 
(a)

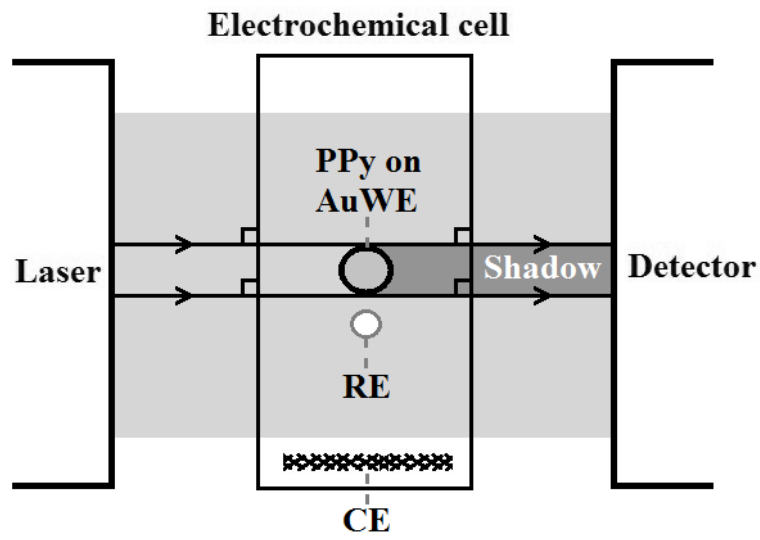

(b)

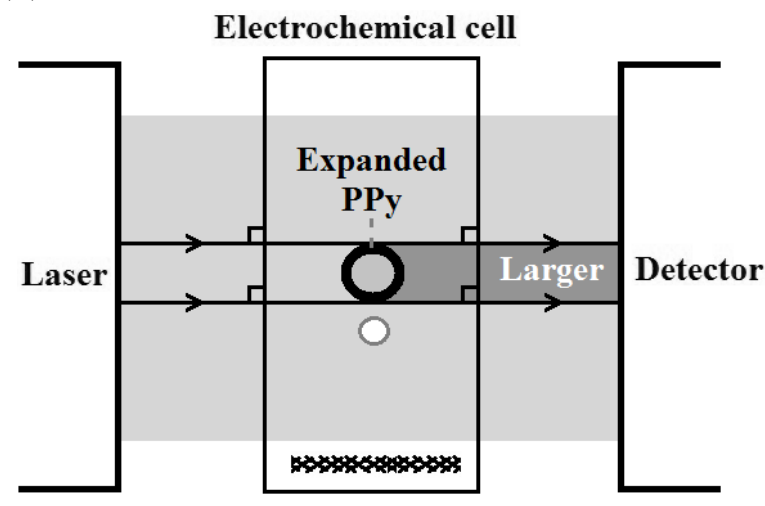

Figure 1. Plan view of the setup illustrating the principle of dimensional measurement using the LSM. (a) Shows the shadow cast by the cross-section of the PPy coated AuWE. (b) Shows the increase in the shadow due to the increase in the diameter caused by the expansion of the polymer film. 
(a)

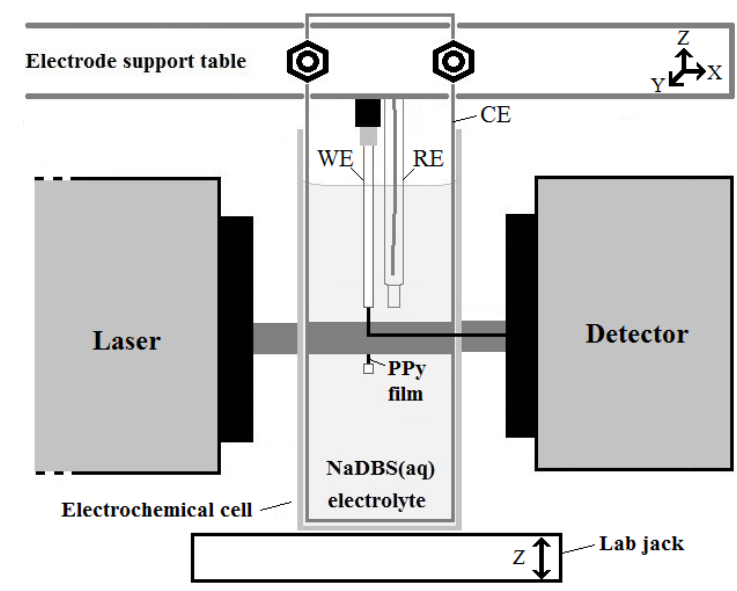

(b)

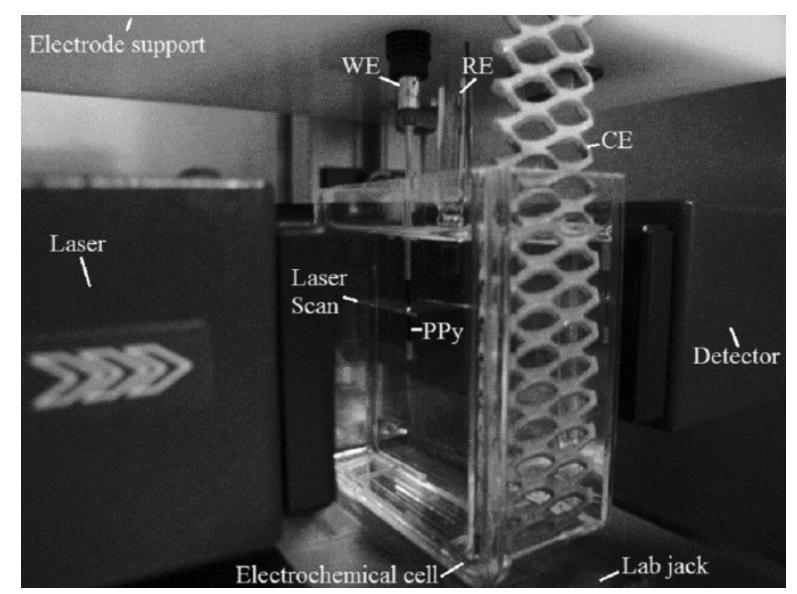

Figure 2. (a) A depiction of the electrochemical cell arrangement used to make actuation measurements. The scanning laser passes through the transparent electrochemical cell undisturbed until it meets the PPy coated AuWE which blocks its path and casts a shadow on the detector equal to its diameter. (b) a photograph of the setup during actuation measurement. 


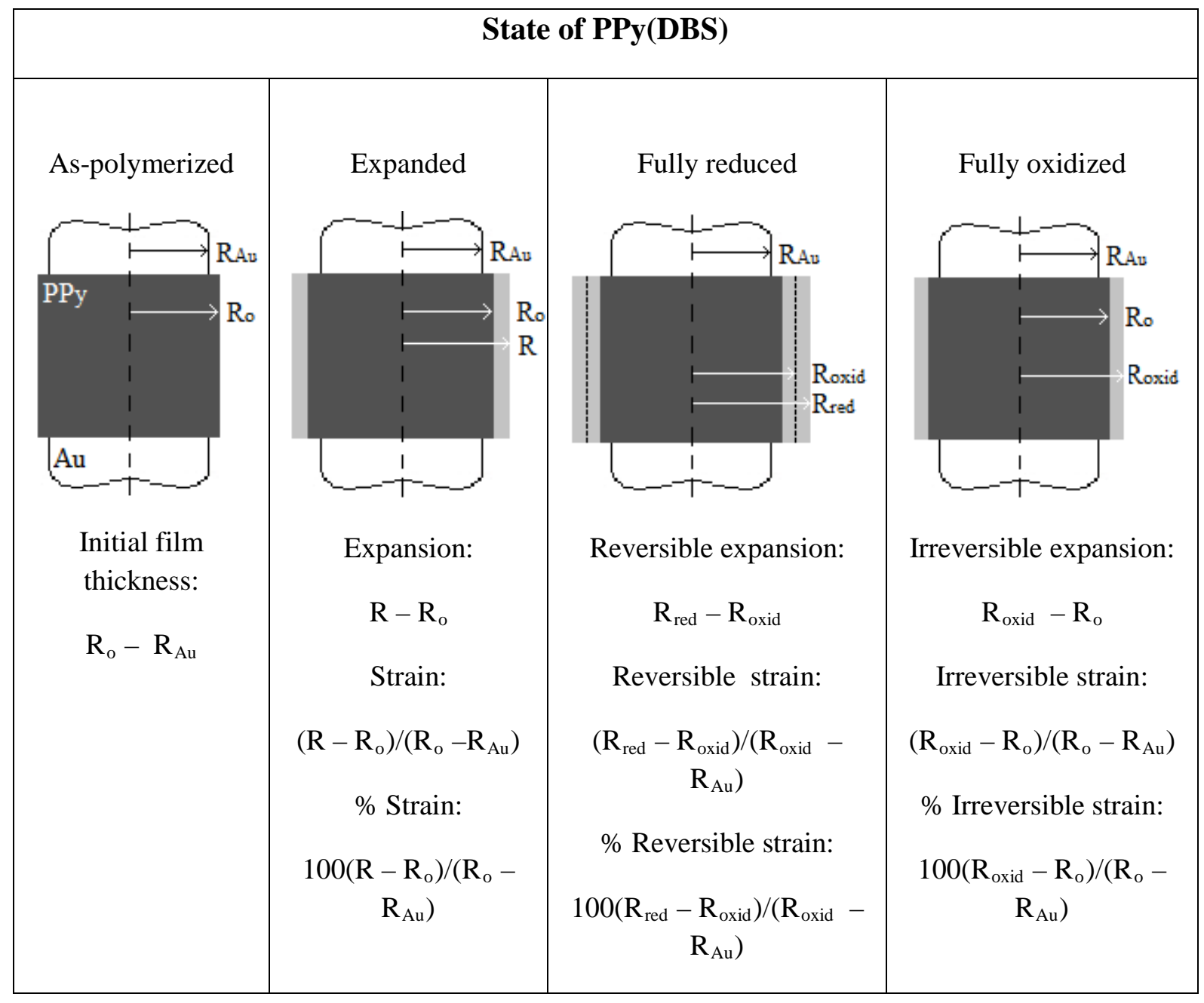

Table 1. Expressions used to calculate expansion and strain. Key: AuWE (gold working electrode), R (general term for radius), $\mathrm{R}_{\mathrm{Au}}$ (radius of AuWE), $\mathrm{R}_{\mathrm{o}}$ (initial radius of the "as-polymerized" PPy film + $R_{\text {Au }}$ ), $R_{\text {red }}$ (radius of the fully reduced PPy film $+R_{\text {Au }}$ ), $R_{\text {oxid }}$ (radius of the fully oxidized PPy film + $\mathrm{R}_{\mathrm{Au}}$ ). 


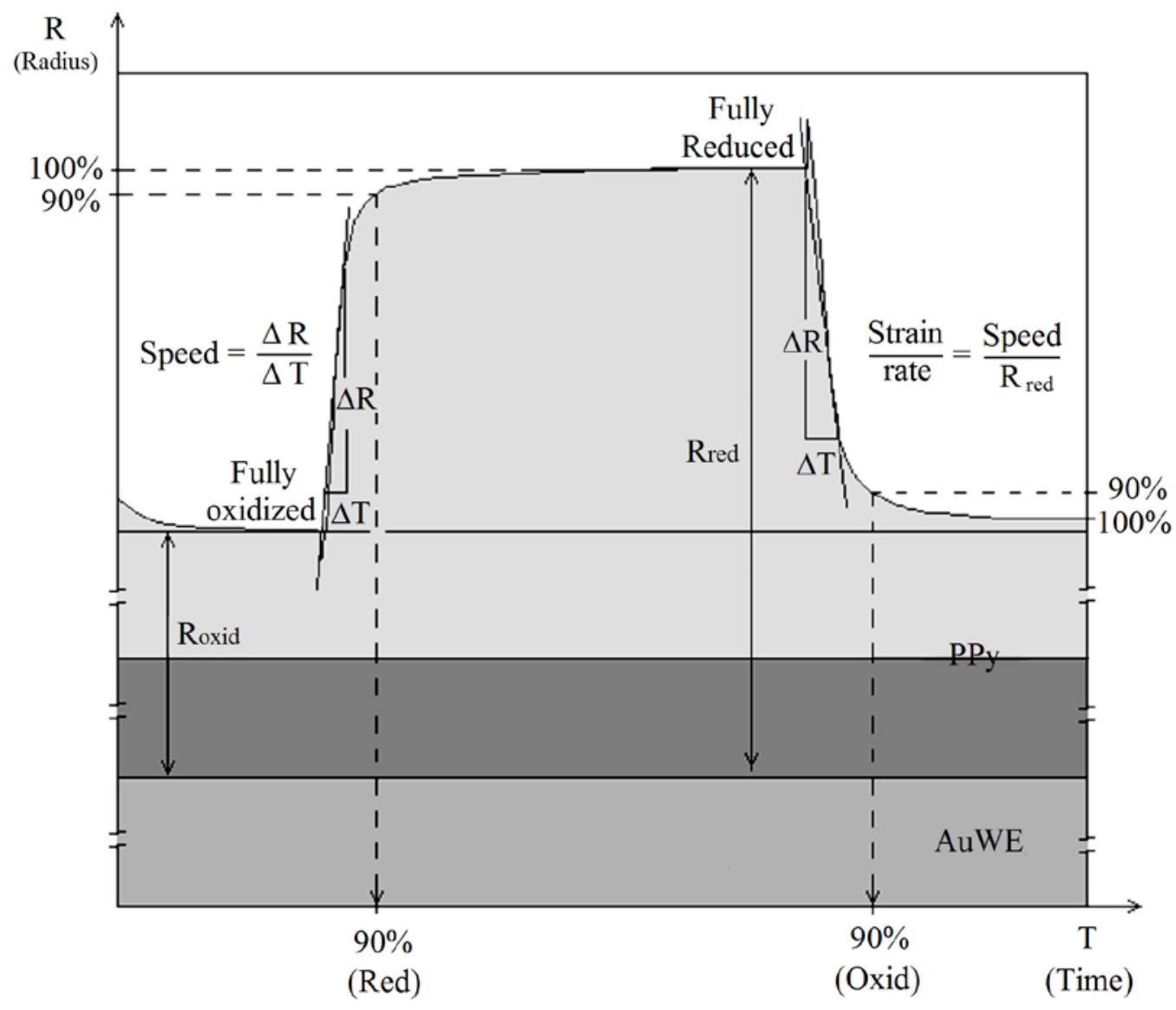

Figure 3. Metrics used to represent how fast the PPy films actuate: expansion rate (speed), strain rate and time taken to reach $90 \%$ maximum reversible expansion. 


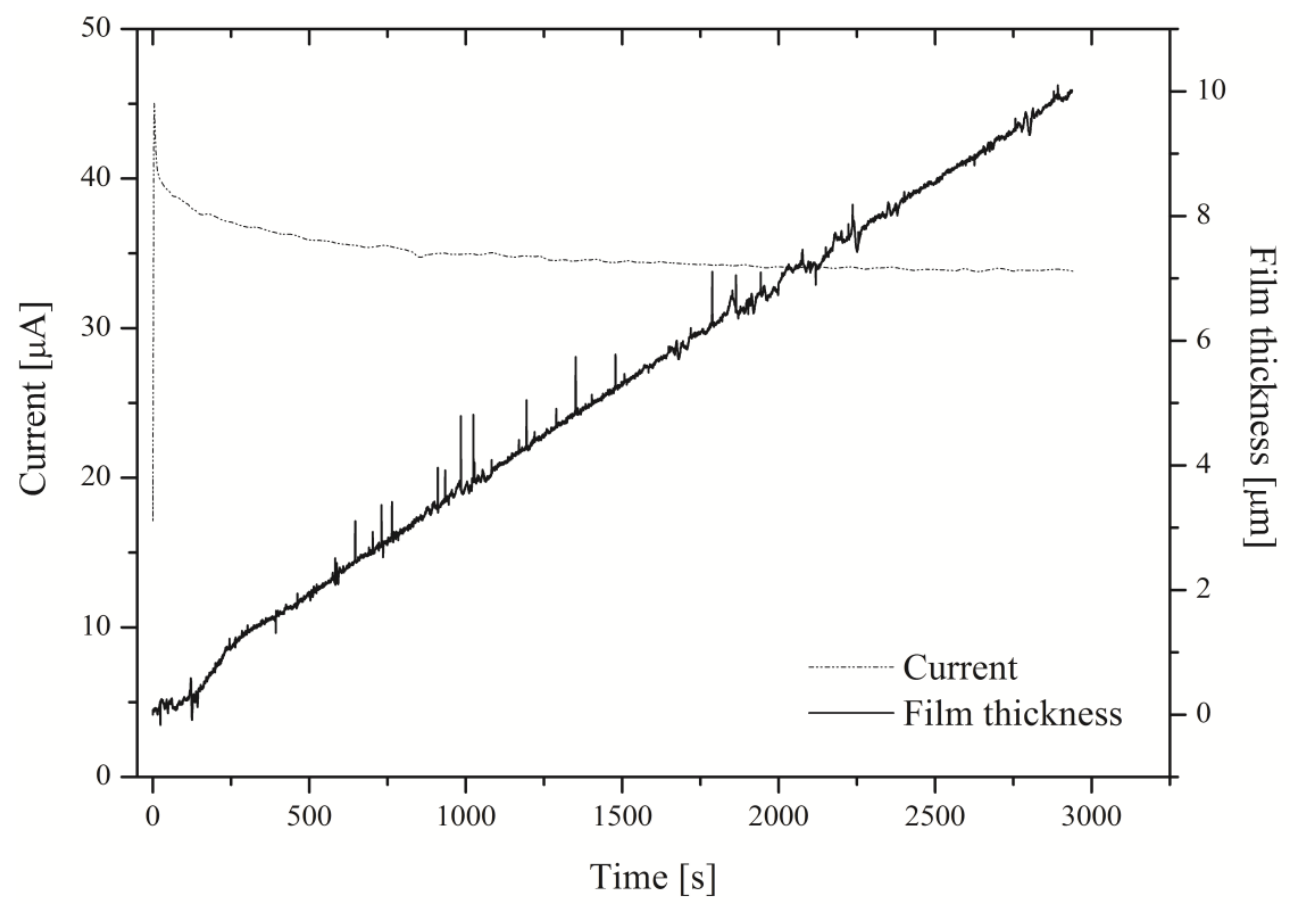

Figure 4. Graphs showing the current and film thickness recorded during the polymerization of a 10 $\mu \mathrm{m}$ PPy film. Growth is essentially linear with slight instability and "spiking”. Spiking might be due to the presence of particulate matter in the unfiltered polymerization solutions. 
(a)

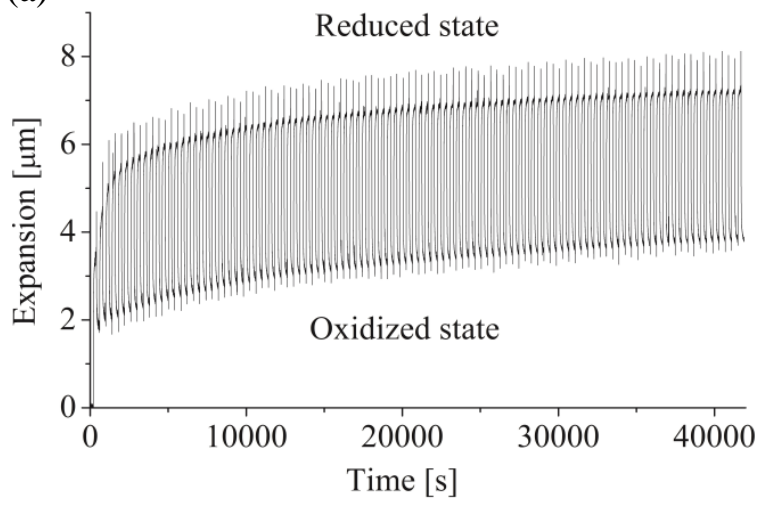

(b)

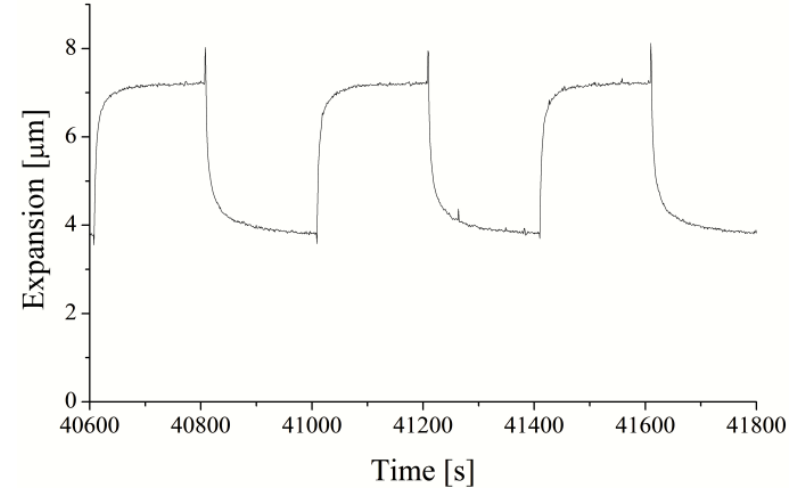

Figure 5. (a) A typical profile of an actuation sequence. In this case PPy film was $10 \mu \mathrm{m}$ thick (b) Enlarged (“zoomed in”) section showing details of a few cycles. 




Figure 6. Changes in reversible expansion and irreversible expansion with cycle number for a $10 \mu \mathrm{m}$ film of PPy(DBS). Note: the reversible component stabilises relatively quickly and reaches its maximum early on in the sequence, typically by cycle 10 . After a large increase during the first cycle, the irreversible expansion, displays a slower more gradual increase reaching a stable, maximum between 70 - 80 cycles. 


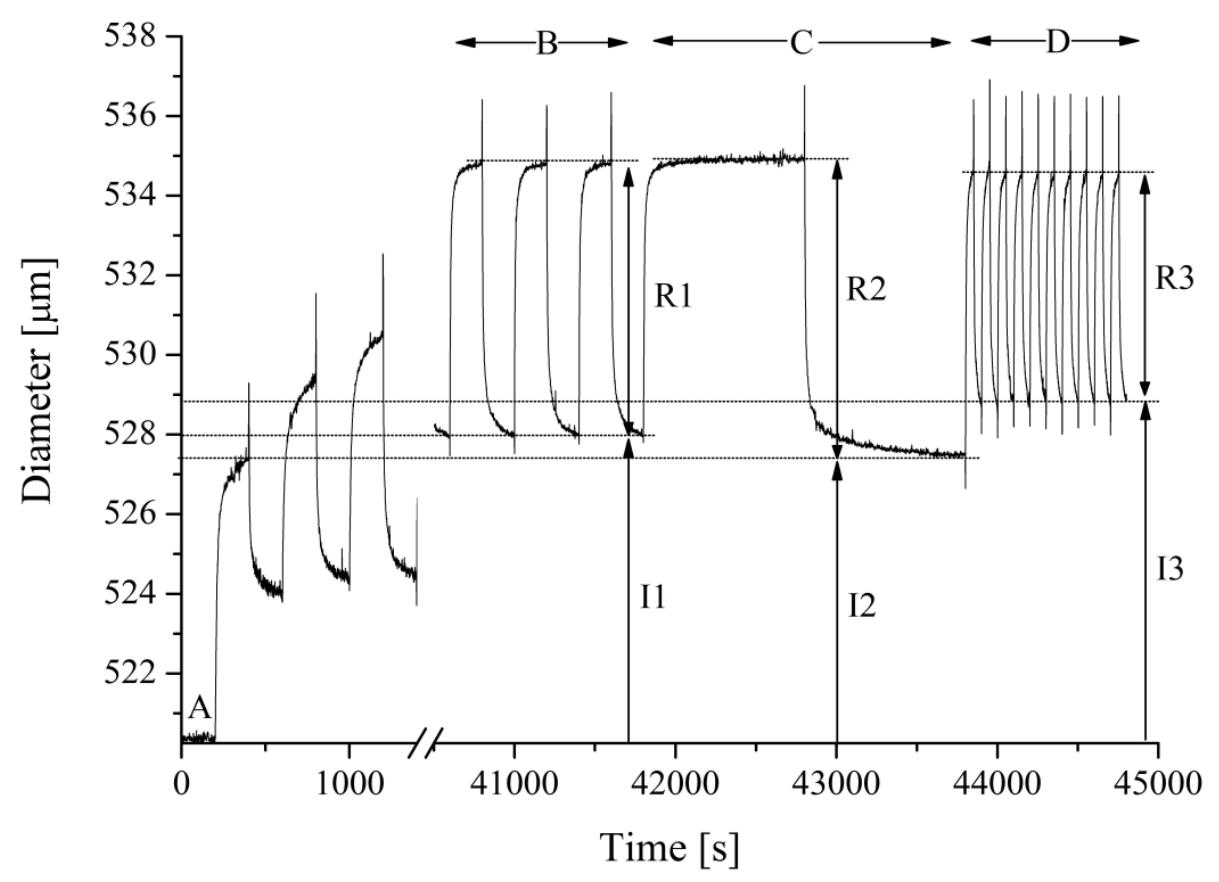

Figure 7. The effect of different cycle times on the reversible and irreversible expansion for the same $10 \mu \mathrm{m}$ film of PPy(DBS). Region B cycle times: $400 \mathrm{~s}$ (-1 V (200 s), 0 V (200 s)); Region C: $2000 \mathrm{~s}$ (-1 V (1000s), 0 V (1000s)); Region D: 100 s (-1 V (50 s), 0 V (50 s)). 
(a)

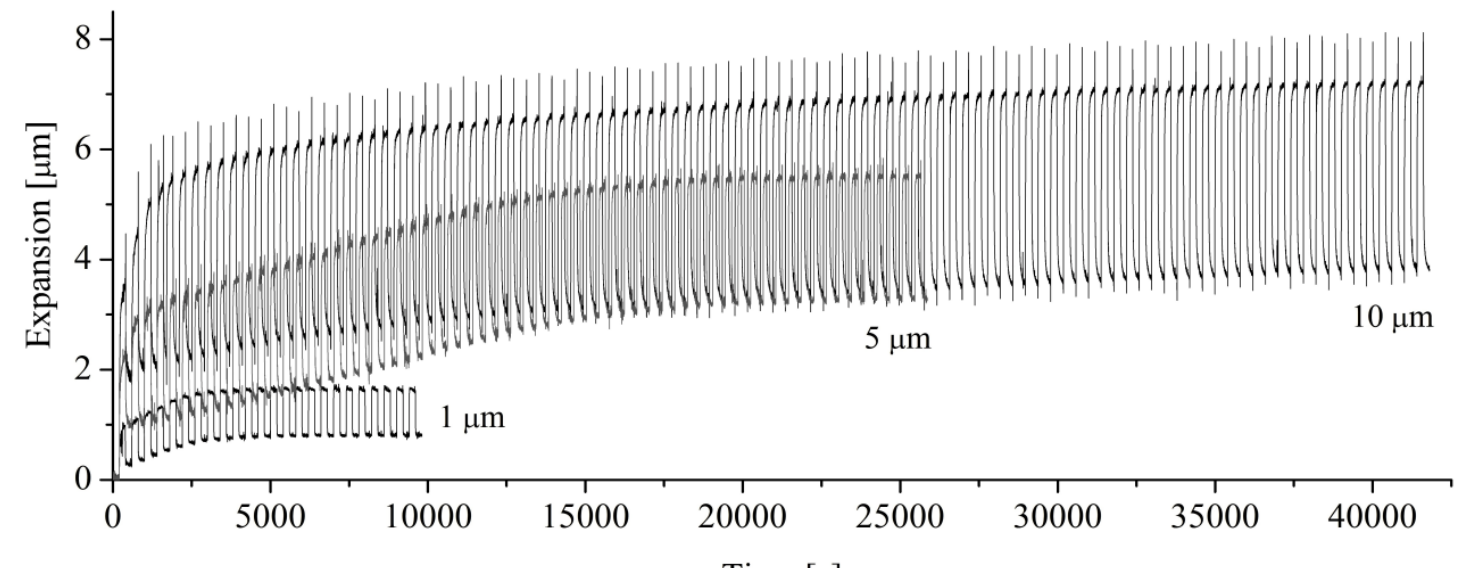

(b) $1 \mu \mathrm{m}$

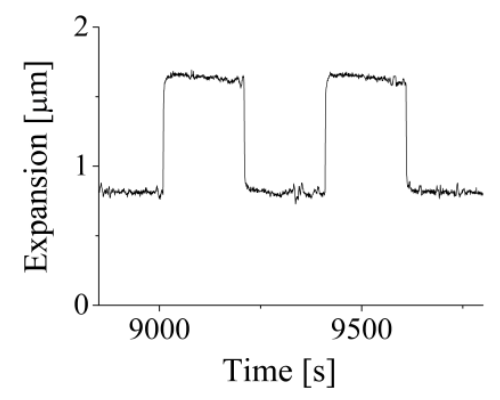

(c) $5 \mu \mathrm{m}$

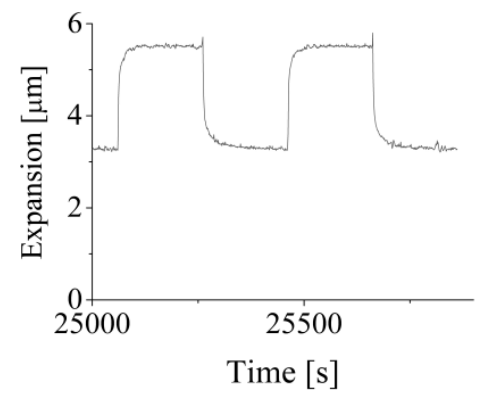

(d) $10 \mu \mathrm{m}$

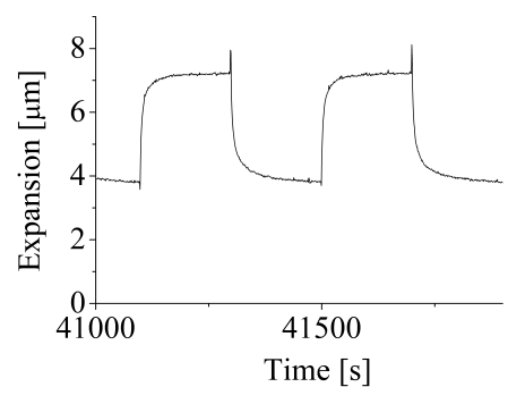

Figure 8. (a) Overlay of typical sequences obtained for 1,5 and $10 \mu \mathrm{m}$ PPy(DBS) films. (b-d) Enlarged (zoomed) cycles taken from the end of the sequence showing the actuation profiles in greater detail. 
(a)

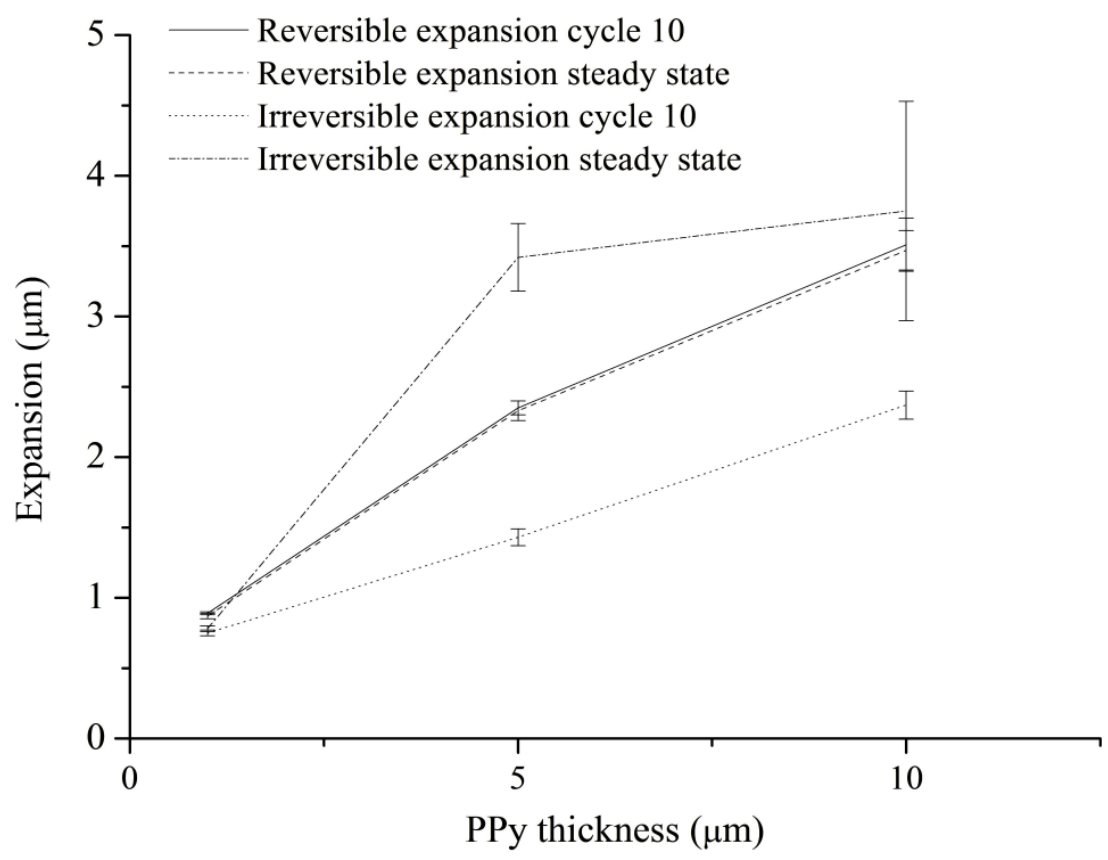

(b)

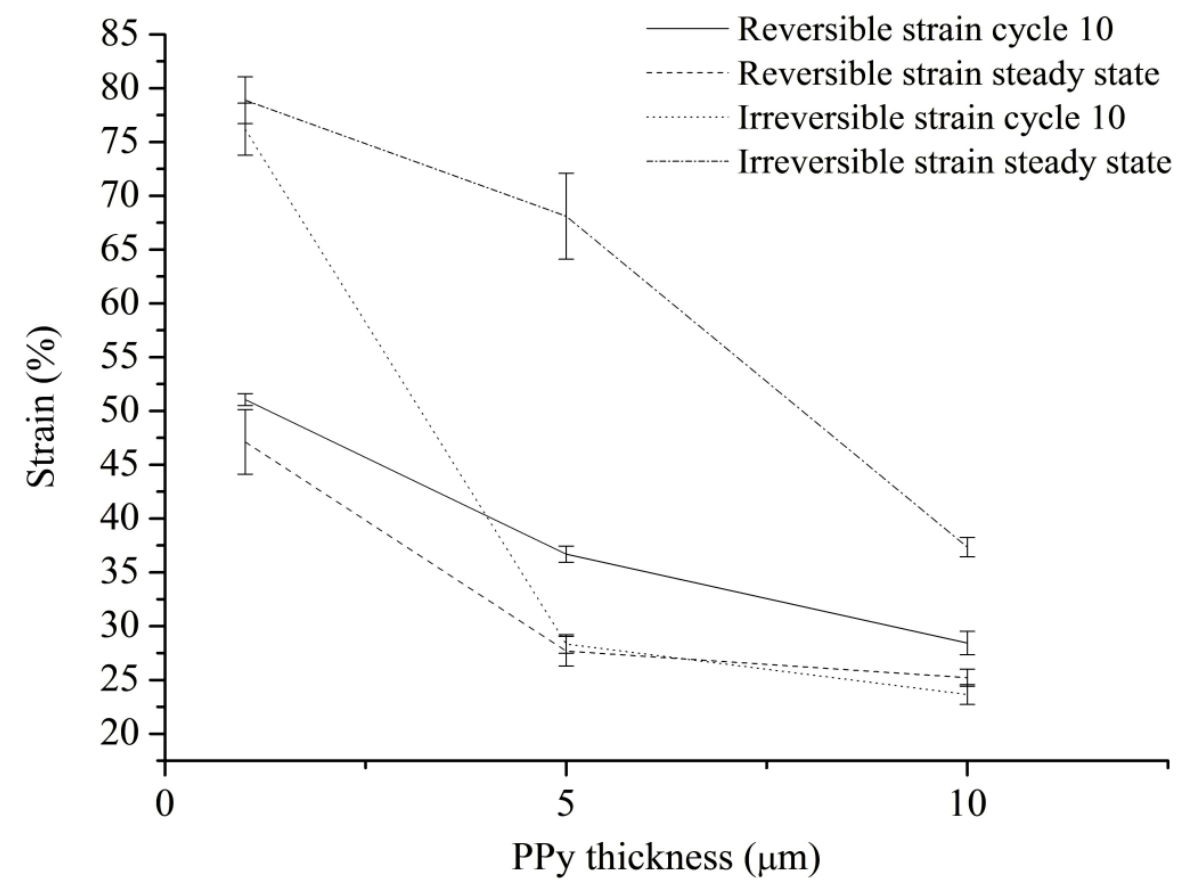

Figure 9. (a) Expansion vs. film thickness and (b) Strain vs. film thickness. Error bars $=1$ SD. 
(a)

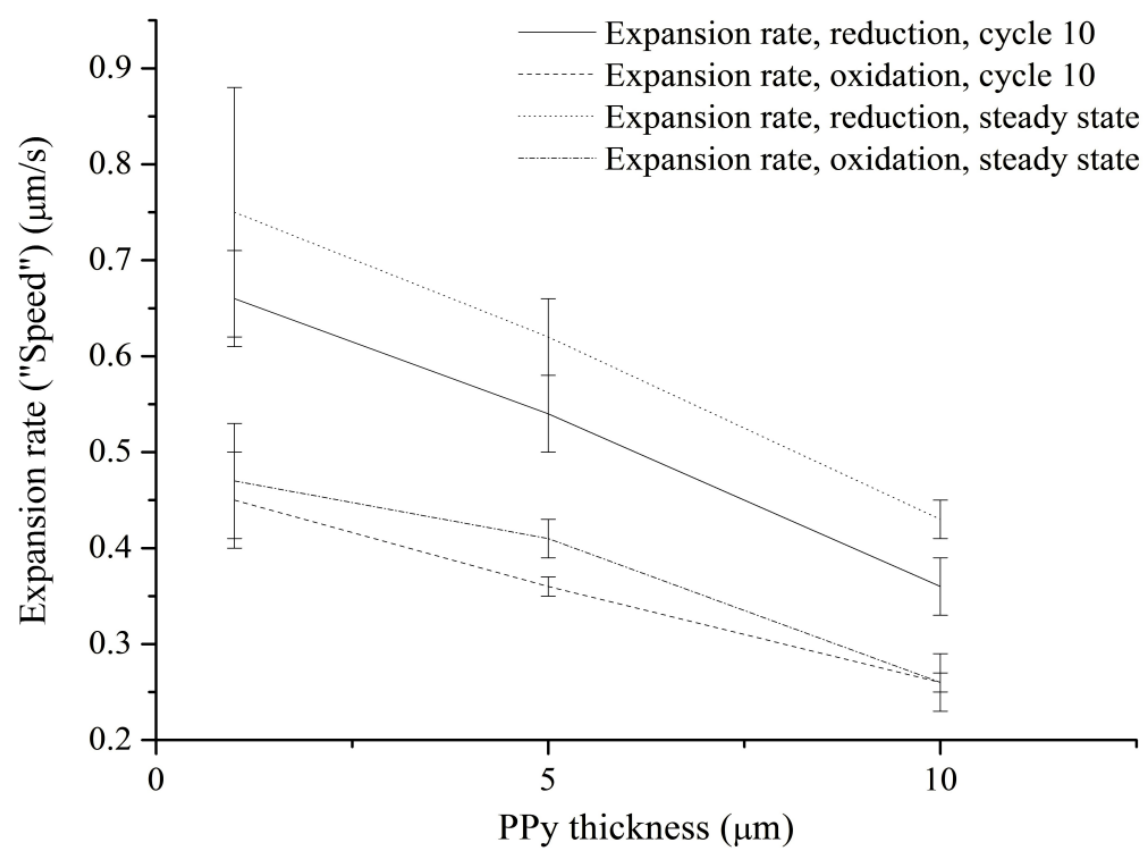

(b)

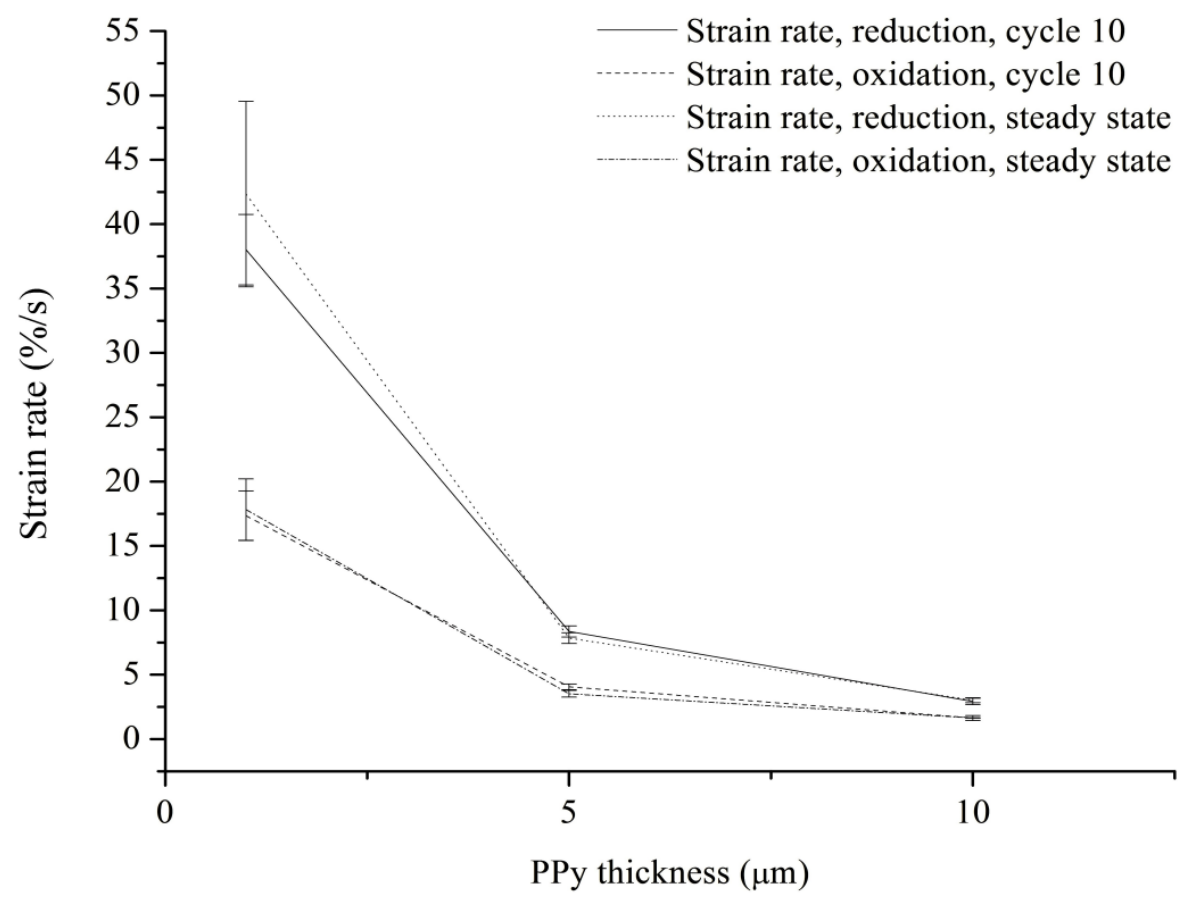


(c)

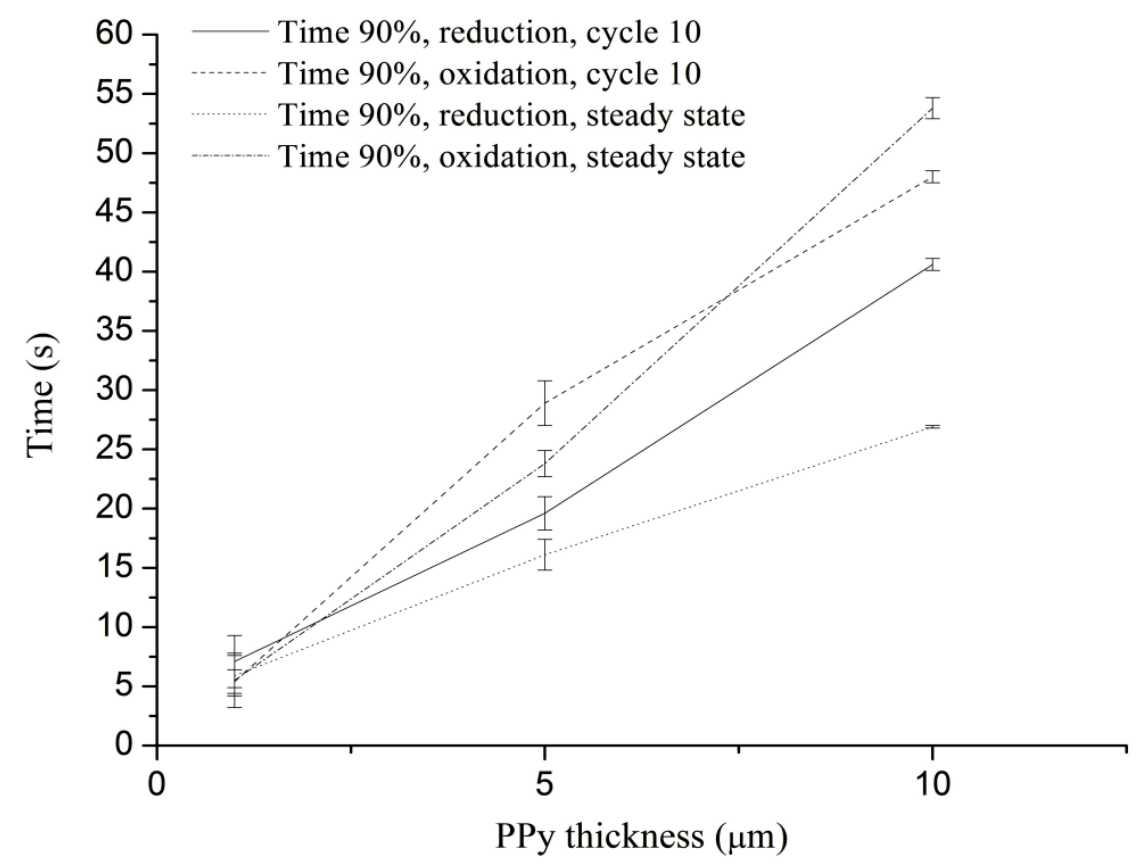

Figure 10. (a) Expansion rate vs. thickness (b) Strain rate vs. thickness. (c) Time to 90\% maximum expansion. Error bars $=1 \mathrm{SD}$ 


\section{Supplementary Material}

(a)

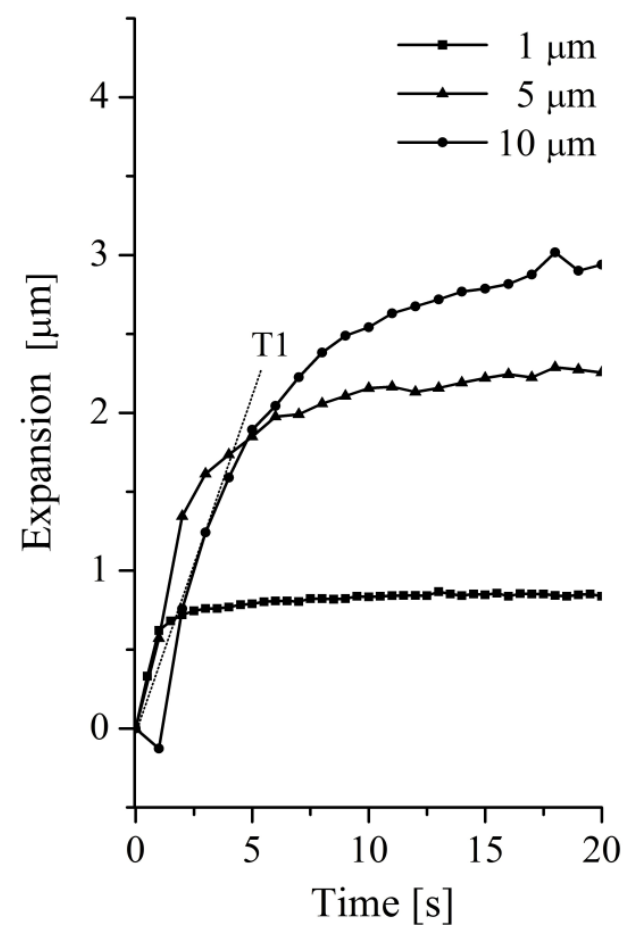

(b)

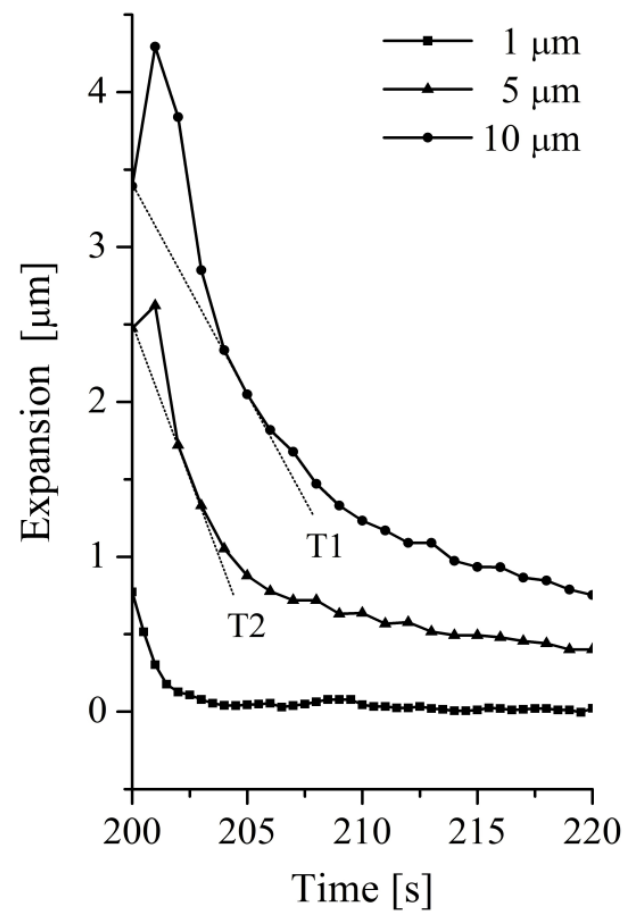

Figure S1. Detail of the first 20 seconds of (a) the reduction and (b) oxidation scans of 1, 5 \& $10 \mu \mathrm{m}$ PPy(DBS) films during the stable state. 


\begin{tabular}{|c|c|c|c|c|c|c|}
\hline Film thickness & \multicolumn{2}{|c|}{$1 \mu \mathrm{m}$} & \multicolumn{2}{|c|}{$5 \mu \mathrm{m}$} & \multicolumn{2}{|c|}{$10 \mu \mathrm{m}$} \\
\hline Position in cycle & $\begin{array}{c}\text { Cycle } \\
10\end{array}$ & $\begin{array}{c}\text { Steady } \\
\text { State }\end{array}$ & $\begin{array}{c}\text { Cycle } \\
10\end{array}$ & $\begin{array}{c}\text { Steady } \\
\text { State }\end{array}$ & $\begin{array}{c}\text { Cycle } \\
10\end{array}$ & $\begin{array}{c}\text { Steady } \\
\text { State }\end{array}$ \\
\hline $\begin{array}{l}\text { Max. Reversible } \\
\text { Expansion } \\
\text { (reduction) }[\mu \mathrm{m}]\end{array}$ & $\begin{array}{c}0.89 \\
\pm 0.01\end{array}$ & $\begin{array}{c}0.87 \\
\pm 0.02\end{array}$ & $\begin{array}{r}2.35 \\
\pm 0.05\end{array}$ & $\begin{array}{c}2.33 \\
\pm 0.07\end{array}$ & $\begin{array}{c}3.51 \\
\pm 0.19\end{array}$ & $\begin{array}{c}3.47 \\
\pm 0.14\end{array}$ \\
\hline $\begin{array}{l}\text { Max. Reversible } \\
\text { Strain } \\
\text { (reduction) [\%] }\end{array}$ & $\begin{array}{r}51.06 \\
\pm 0.55\end{array}$ & $\begin{array}{c}47.13 \\
\pm 3.00\end{array}$ & $\begin{array}{r}36.69 \\
\pm 0.75\end{array}$ & $\begin{array}{c}27.67 \\
\pm 1.37\end{array}$ & $\begin{array}{r}28.43 \\
\pm 1.09\end{array}$ & $\begin{array}{c}25.21 \\
\pm 0.79\end{array}$ \\
\hline $\begin{array}{l}\text { Max. Irreversible } \\
\text { Expansion } \\
\text { (oxidation) }[\mu \mathrm{m}] \\
\end{array}$ & $\begin{array}{c}0.75 \\
\pm 0.02\end{array}$ & $\begin{array}{c}0.78 \\
\pm 0.02\end{array}$ & $\begin{array}{c}1.43 \\
\pm 0.06\end{array}$ & $\begin{array}{c}3.42 \\
\pm 0.24\end{array}$ & $\begin{array}{c}2.37 \\
\pm 0.10\end{array}$ & $\begin{array}{c}3.75 \\
\pm 0.78\end{array}$ \\
\hline $\begin{array}{l}\text { Max. Irreversible } \\
\text { Strain } \\
\text { (oxidation) }[\mu \mathrm{m}]\end{array}$ & $\begin{array}{r}76.19 \\
\pm 2.42\end{array}$ & $\begin{array}{r}78.89 \\
\pm 2.18\end{array}$ & $\begin{array}{r}28.34 \\
\pm 0.86\end{array}$ & $\begin{array}{r}68.10 \\
\pm 4.00\end{array}$ & $\begin{array}{r}23.64 \\
\pm 0.92\end{array}$ & $\begin{array}{c}37.35 \\
\pm 0.89\end{array}$ \\
\hline $\begin{array}{c}\text { Max. Reversible } \\
\text { Expansion Rate } \\
\text { (reduction) }[\mu \mathrm{m} / \mathrm{s}]\end{array}$ & $\begin{array}{c}0.66 \\
\pm 0.05\end{array}$ & $\begin{array}{c}0.75 \\
\pm 0.13\end{array}$ & $\begin{array}{c}0.54 \\
\pm 0.04\end{array}$ & $\begin{array}{c}0.62 \\
\pm 0.04\end{array}$ & $\begin{array}{c}0.36 \\
\pm 0.03\end{array}$ & $\begin{array}{c}0.43 \\
\pm 0.02\end{array}$ \\
\hline $\begin{array}{c}\text { Max. Reversible } \\
\text { Expansion Rate } \\
\text { (oxidation) }[\mu \mathrm{m} / \mathrm{s}]\end{array}$ & $\begin{array}{c}0.45 \\
\pm 0.05\end{array}$ & $\begin{array}{c}0.47 \\
\pm 0.06\end{array}$ & $\begin{array}{c}036 \\
\pm 0.01\end{array}$ & $\begin{array}{c}0.41 \\
\pm 0.02\end{array}$ & $\begin{array}{c}0.26 \\
\pm 0.01\end{array}$ & $\begin{array}{c}0.26 \\
\pm 0.03\end{array}$ \\
\hline $\begin{array}{c}\text { Max. Reversible } \\
\text { Strain Rate } \\
\text { (reduction) }[\% / s]\end{array}$ & $\begin{array}{c}38.02 \\
\pm 2.74\end{array}$ & $\begin{array}{r}42.34 \\
\pm 7.21\end{array}$ & $\begin{array}{c}8.36 \\
\pm 0.43\end{array}$ & $\begin{array}{c}7.85 \\
\pm 0.42\end{array}$ & $\begin{array}{c}2.92 \\
\pm 0.25\end{array}$ & $\begin{array}{c}3.02 \\
\pm 0.19\end{array}$ \\
\hline $\begin{array}{c}\text { Max. Reversible } \\
\text { Strain Rate } \\
\text { (oxidation) }[\% / s]\end{array}$ & $\begin{array}{l}-17.35 \\
\pm 1.93\end{array}$ & $\begin{array}{l}-17.83 \\
\pm 2.38\end{array}$ & $\begin{array}{c}-4.06 \\
\pm 0.22\end{array}$ & $\begin{array}{c}-3.52 \\
\pm 0.26\end{array}$ & $\begin{array}{c} \\
-1.64 \\
\pm 0.02\end{array}$ & $\begin{array}{c}-1.64 \\
\pm 0.19\end{array}$ \\
\hline $\begin{array}{l}\text { Time to } 90 \% \text { Max. } \\
\text { Reversible Expansion } \\
\text { (reduction) [s] }\end{array}$ & $\begin{array}{c}7.1 \\
\pm 2.2\end{array}$ & $\begin{array}{c}5.9 \\
\pm 1.7\end{array}$ & $\begin{array}{l}19.6 \\
\pm 1.4\end{array}$ & $\begin{array}{c}16.1 \\
\pm 1.3\end{array}$ & $\begin{array}{r}40.6 \\
\pm 0.5\end{array}$ & $\begin{array}{c}26.9 \\
\pm 0.1\end{array}$ \\
\hline $\begin{array}{l}\text { Time to } 90 \% \text { Max. } \\
\text { Reversible Expansion } \\
\text { (oxidation) [s] }\end{array}$ & $\begin{array}{c}5.4 \\
\pm 1.0\end{array}$ & $\begin{array}{c}5.5 \\
\pm 2.3\end{array}$ & $\begin{array}{r}28.9 \\
\pm 1.9\end{array}$ & $\begin{array}{c}23.8 \\
\pm 1.1\end{array}$ & $\begin{array}{r}48.0 \\
\pm 0.5\end{array}$ & $\begin{array}{c}53.8 \\
\pm 0.9\end{array}$ \\
\hline
\end{tabular}

Table S1. Actuation metrics for PPy(DBS) films in the range 1 to $10 \mu \mathrm{m}$. Note: all metrics where obtained using three different replicate samples at each thickness and are given as the Mean \pm 1 SD. 


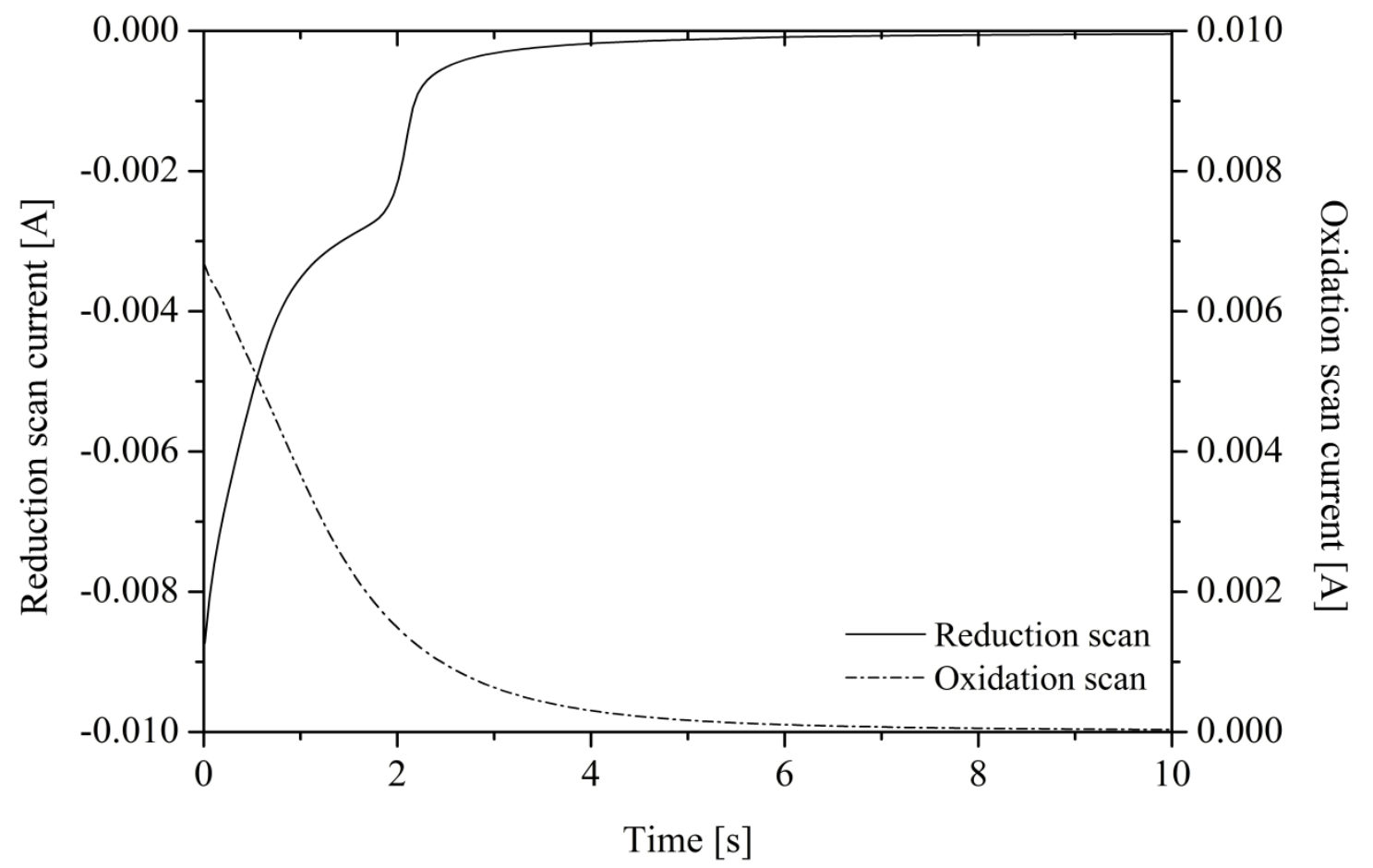

Figure S2. Current during both the oxidation and reduction scans for a $5 \mu \mathrm{m}$ PPy(DBS) film actuated in the steady state. 


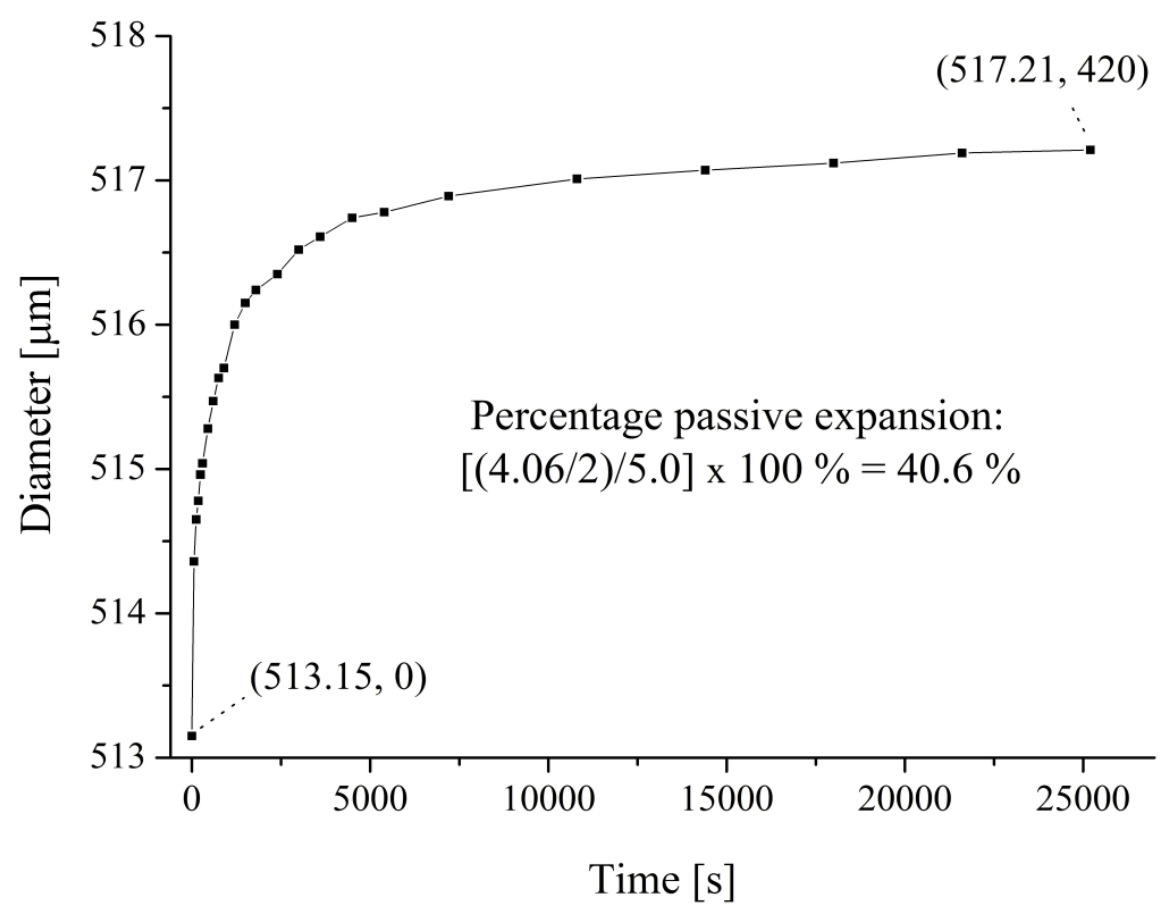

Figure S3. Passive expansion of a $5 \mu \mathrm{m}$ PPy(DBS) film on the surface of a AuWE (initial diameter $(\mathrm{Au}+\mathrm{PPy})=513.15 \mu \mathrm{m})$ in contact with $0.1 \mathrm{M} \mathrm{NaDBS}(\mathrm{aq})$ without any external influence. 


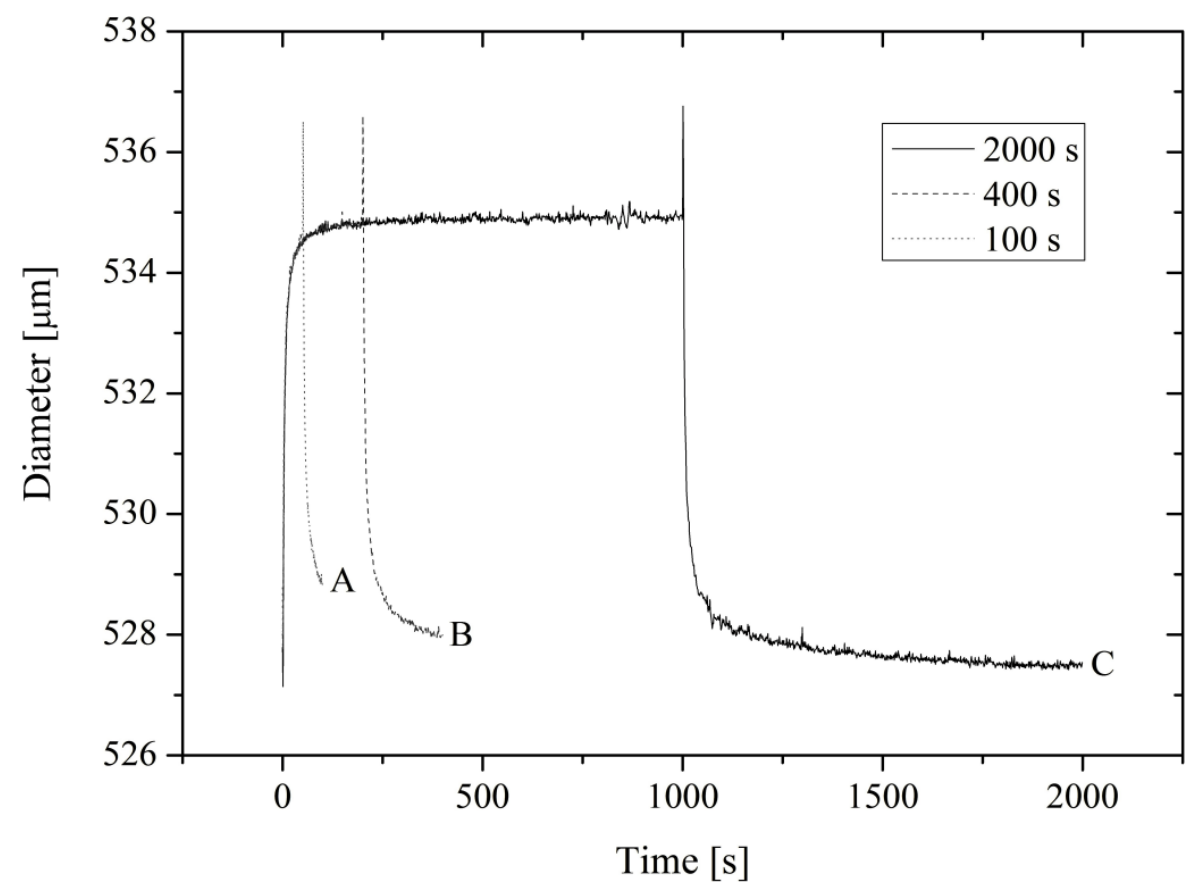

Figure S4. Expansion as a function of cycle length. 